\title{
Is There a "Tipping Point" between Simulated Nontornadic and Tornadic Supercells in VORTEX2 Environments? 0
}

\author{
Brice E. COFFER AND MATTHEW D. PARKER \\ Department of Marine, Earth, and Atmospheric Sciences, North Carolina State University at Raleigh, \\ Raleigh, North Carolina
}

(Manuscript received 8 February 2018, in final form 19 June 2018)

\begin{abstract}
Previous work has suggested that the lower-tropospheric wind profile may partly determine whether supercells become tornadic. If tornadogenesis within the VORTEX2 composite environments is more sensitive to the lowertropospheric winds than to either the upper-tropospheric winds or the thermodynamic profile, then systematically varying the lower-tropospheric wind profile might reveal a "tipping point" between nontornadic and tornadic supercells. As a test, simulated supercells are initiated in environments that have been gradually interpolated between the low-level wind profiles of the nontornadic and tornadic VORTEX2 supercell composites while also interchanging the upper-tropospheric winds and thermodynamic profile. Simulated supercells become tornadic when the low-level wind profile incorporates at least $40 \%$ of the structure from the tornadic VORTEX2 composite environment. Both the nontornadic and tornadic storms have similar outflow temperatures and availability of surface vertical vorticity near their updrafts. Most distinctly, a robust low-level mesocyclone and updraft immediately overlie the intensifying near-surface circulation in each of the tornadic supercells. The nontornadic supercells have low-level updrafts that are disorganized, with pockets of descent throughout the region where surface vertical vorticity resides. The lower-tropospheric wind profile drives these distinct configurations of the low-level mesocyclone and updraft, regardless of the VORTEX2 composite upper-tropospheric wind profile or thermodynamic profile. This study therefore supports a potentially useful, robust link between the probability of supercell tornadogenesis and the lower-tropospheric wind profile, with tornadogenesis more (less) likely when the orientation of horizontal vorticity in the lowest few hundred meters is streamwise (crosswise).
\end{abstract}

\section{Introduction}

The environmental proxies currently used operationally for diagnosing the strength and organization of the low-level mesocyclone in supercells [i.e., $0-1 \mathrm{~km}$ and effective-layer storm-relative helicity (SRH)] have led to stark improvements in our ability to forecast significantly tornadic supercells (e.g., Thompson et al. 2003, 2007). Unfortunately, despite these advances, our ability to distinguish between nontornadic and tornadic supercell scenarios in real time is still limited, likely because our understanding of environmental controls on tornado formation is incomplete (Anderson-Frey et al. 2016). This deficiency is manifested in a rather high false alarm ratio for tornado warnings in the United States $(\sim 75 \%$; Brotzge

Supplemental information related to this paper is available at the Journals Online website: https://doi.org/10.1175/MWR-D-180050.s1.

Corresponding author: Brice Coffer, becoffer@ncsu.edu et al. 2011), which roughly corresponds to the percentage of supercells that do not produce tornadoes (at least $75 \%$; Trapp et al. 2005). Understanding how differences in environmental profiles affect the in-storm processes that lead to tornadogenesis (or tornadogenesis failure) would seem essential to improving forecasts and warnings for tornadoes.

Recently, a number of studies have addressed this problem using high-resolution simulations (e.g., Markowski and Richardson 2014, 2017; Naylor and Gilmore 2014; Coffer and Parker 2015; Guarriello et al. 2018). Among these, both Coffer and Parker (2017, hereafter C17a) and Coffer et al. (2017, hereafter C17b) explored the processes whereby subtornadic ${ }^{1}$ surface $^{2}$

\footnotetext{
${ }^{1}$ In this paper, "subtornadic vorticity", will refer to mesocyclonicscale vertical vorticity $\left(\geq 0.01 \mathrm{~s}^{-1}\right)$ at the surface that is not (yet) associated with a tornado.

${ }^{2}$ In this paper, "surface," "near surface," or "near ground" will refer to $\leq 10 \mathrm{~m}$ AGL (the lowest model-level grid point), while "low level" refers to $\sim 1 \mathrm{~km}$ AGL, and "midlevel" refers to 3-7 km AGL.
} 

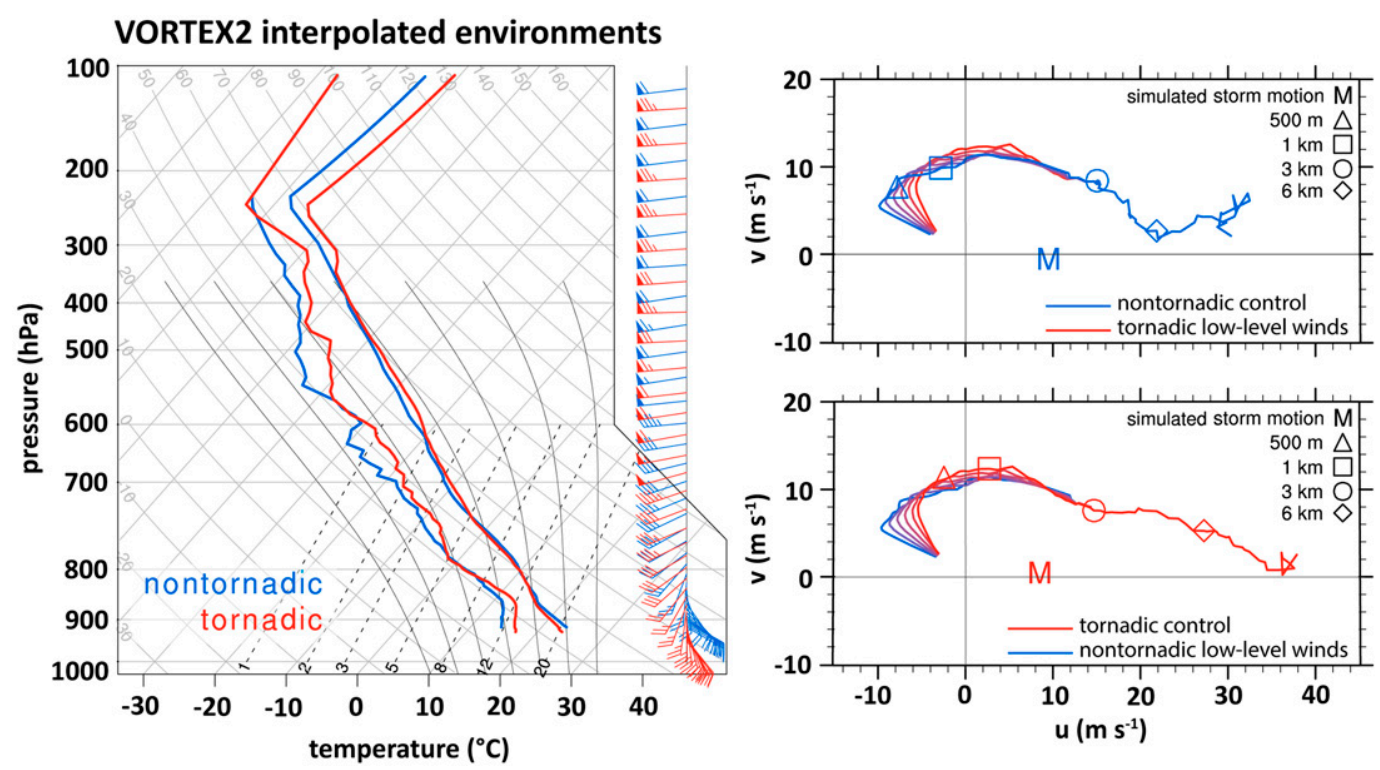

FIG. 1. (left) Skew $T$ - $\log p$ diagram and (right) hodographs showing the (top) nontornadic (blue) and (bottom) tornadic (red) VORTEX2 near-inflow composite environments. The interpolated LLW profiles $(20 \%, 40 \%, 60 \%$, and $80 \%$ ) for the respective VORTEX2 profiles are shown in each hodograph diagram. Winds above $2.5 \mathrm{~km}$ are identical in each of the five sensitivity tests for both the nontornadic and tornadic VORTEX2 environments. The simulated storm motion is indicated on the hodograph by the "M" marker. The storm motions between the sensitivity tests are nearly identical; thus, only one marker is plotted. Markers on the hodograph represent $500 \mathrm{~m}$ (triangle), $1 \mathrm{~km}$ (square), $3 \mathrm{~km}$ (circle), and $6 \mathrm{~km}$ (diamond) AGL. The wind barbs on the skew $T-\log p$ are displayed in kt $\left(1 \mathrm{kt}=0.5144 \mathrm{~m} \mathrm{~s}^{-1}\right)$. See Parker (2014) for more discussion on the generation and interpretation of the VORTEX2 composite environments.

vertical vorticity can be converged and stretched into a tornado by initializing simulations with nontornadic and tornadic environmental composite profiles sampled during the second Verification of the Origins of Rotation in Tornadoes Experiment (VORTEX2; Wurman et al. 2012). One of the most notable differences in the composite VORTEX2 supercell environments from Parker (2014) is that the tornadic wind profile has considerably more streamwise horizontal vorticity in the near-ground layer. For the tornadic wind profile, this leads to larger 0-500-m SRH (159 vs $80 \mathrm{~m}^{2} \mathrm{~s}^{-2}$ ), larger 0-1-km SRH
(224 vs $151 \mathrm{~m}^{2} \mathrm{~s}^{-2}$ ), and a critical angle (Esterheld and Giuliano 2008) that is approximately $90^{\circ}$ (implying purely streamwise horizontal environmental vorticity) as opposed to $140^{\circ}$ (implying environmental horizontal vorticity that is majority crosswise) in the nontornadic wind profile. C17a found that these differences in wind profiles contain sufficient information to "correctly" simulate tornadic versus nontornadic supercells. Predominately streamwise horizontal vorticity in the lowest few hundred meters of the ambient environment in the tornadic VORTEX2 environment promoted a more intense

TABLE 1. CM1 configuration.

\begin{tabular}{ll}
\hline \multicolumn{1}{c}{ Parameter } & \multicolumn{1}{c}{ Description } \\
\hline Domain extent & $200 \mathrm{~km} \times 200 \mathrm{~km} \times 18.16 \mathrm{~km}$ \\
Inner mesh & $\Delta x=\Delta y=125 \mathrm{~m}$ spanning $100 \times 100 \mathrm{~km}^{2}$ \\
Outer mesh & Stretching to $\Delta x=\Delta y=4.875 \mathrm{~km}$ (Wilhelmson and Chen 1982) \\
Vertical grid & 115 levels starting at $10 \mathrm{~m}, \Delta z=20 \mathrm{~m}$ below 300 m, stretching to $\Delta z=280 \mathrm{~m}$ at $12 \mathrm{~km}$ \\
Numerics & RK3/fifth-order WENO advection of velocities and scalars (Shu 2003; Wicker and Skamarock 2002) \\
Pressure solver & Klemp-Wilhelmson time-splitting, vertically implicit (Klemp and Wilhelmson 1978) \\
Time step & Adaptive time stepping, initial large time step of 1 s \\
Microphysics & NSSL two-moment (Ziegler 1985; Mansell 2010; Mansell et al. 2010) \\
Subgrid turbulence & TKE (Deardorff 1980) with separate horizontal and vertical eddy viscosity coefficients \\
Bottom boundary condition & Semislip with $C_{d}=0.0014$ (C17a) \\
3D initialization & Updraft nudging (Naylor and Gilmore 2012) \\
\hline
\end{tabular}


TABLE 2. Summary of the 10 simulations initialized with the VORTEX2 interpolated environments and the two control runs (nontornadic and tornadic) from the VORTEX2 ensemble. SRH and streamwise/crosswise horizontal vorticity were calculated using the Bunkers storm motion (Bunkers et al. 2000), which was similar to the simulated storm motion. The tornadogenesis criteria are outlined in section 2 of $\mathrm{C} 17 \mathrm{~b}$. In short, the key time period is either the time of tornadogenesis or the time of maximum surface vertical vorticity, if a supercell did not meet the criteria.

\begin{tabular}{|c|c|c|c|c|c|}
\hline & Acronym & $\begin{array}{c}0-500-\mathrm{m} \\
\mathrm{SRH}\left(\mathrm{m}^{2} \mathrm{~s}^{-2}\right)\end{array}$ & $\begin{array}{c}0-500-\mathrm{m} \\
\text { streamwise/crosswise } \\
\text { vorticity ratio }\end{array}$ & Tornadic? & $\begin{array}{c}\text { Key time } \\
\text { period (min) }\end{array}$ \\
\hline \multicolumn{6}{|c|}{ Tornadic VORTEX2 interpolated simulations } \\
\hline Nontornadic low-level winds & torV2-ntLLW & 93 & 0.64 & Nontornadic & $t=70$ \\
\hline $20 \%$ tornadic low-level winds & torV2-20torLLW & 105 & 0.83 & Nontornadic & $t=53$ \\
\hline $40 \%$ tornadic low-level winds & torV2-40torLLW & 118 & 1.06 & Tornadic & $t=52$ \\
\hline $60 \%$ tornadic low-level winds & torV2-60torLLW & 131 & 1.36 & Tornadic & $t=54$ \\
\hline $80 \%$ tornadic low-level winds & torV2-80torLLW & 144 & 1.63 & Tornadic & $t=52$ \\
\hline Tornadic control & torV2-control & 157 & 1.98 & Tornadic & $t=54$ \\
\hline \multicolumn{6}{|c|}{ Nontornadic VORTEX2 interpolated simulations } \\
\hline Tornadic low-level winds & ntV2-torLLW & 136 & 1.64 & Tornadic & $t=58$ \\
\hline $80 \%$ tornadic low-level winds & ntV2-80torLLW & 126 & 1.33 & Tornadic & $t=62$ \\
\hline $60 \%$ tornadic low-level winds & ntV2-60torLLW & 114 & 1.07 & Weakly tornadic & $t=79$ \\
\hline $40 \%$ tornadic low-level winds & ntV2-40torLLW & 103 & 0.93 & Nontornadic & $t=74$ \\
\hline $20 \%$ tornadic low-level winds & ntV2-20torLLW & 91 & 0.74 & Nontornadic & $t=105$ \\
\hline Nontornadic control & ntV2-control & 79 & 0.58 & Nontornadic & $t=67$ \\
\hline
\end{tabular}

low-level mesocyclone and a more favorable configuration of the low-level mesocyclone for tornadogenesis.

In testing the volatility of this result, $\mathrm{C} 17 \mathrm{~b}$ produced an ensemble of 30 members driven by small perturbations to the initial nontornadic and tornadic VORTEX2 environments. The ensemble suggests that there is at least some component of the probability of tornadogenesis that is stochastic (because $40 \%$ of the ensemble members

\section{Tornadic VORTEX2 interpolated simulations: Reflectivity}

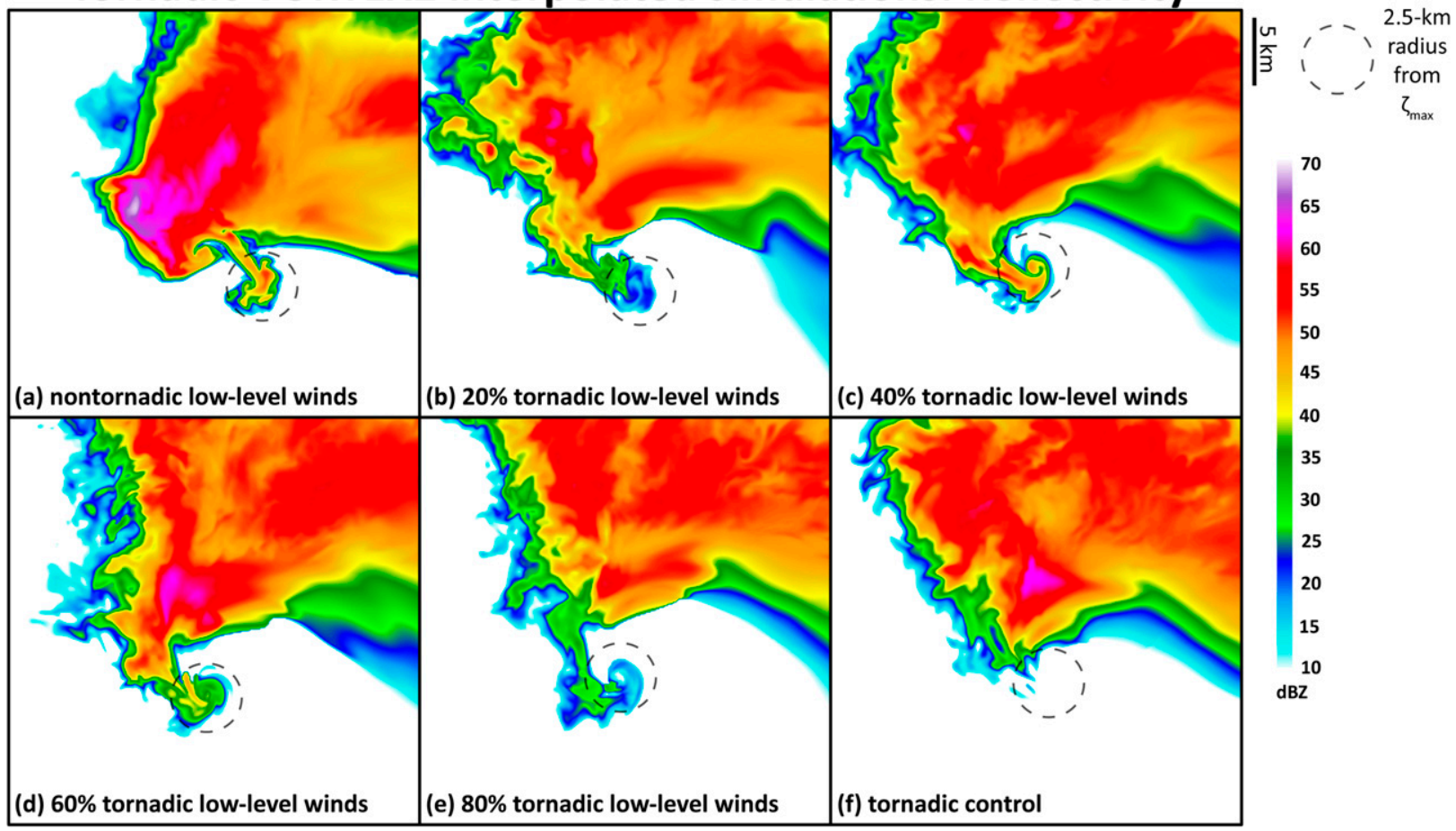

FIG. 2. Horizontal cross sections of $10 \mathrm{~m}$ AGL reflectivity (dBZ; shaded) at the key time period of tornadogenesis or tornadogenesis failure for the tornadic VORTEX2 interpolated simulations. Refer to Table 2 for the key time period for each simulation. The dashed circle in each panel encloses the 2.5-km-radius ring around the surface vertical vorticity maximum at the key time period used in Figs. 5 and 8 . 


\section{Tornadic VORTEX2 interpolated simulations: Translated maximum surface vertical vorticity}

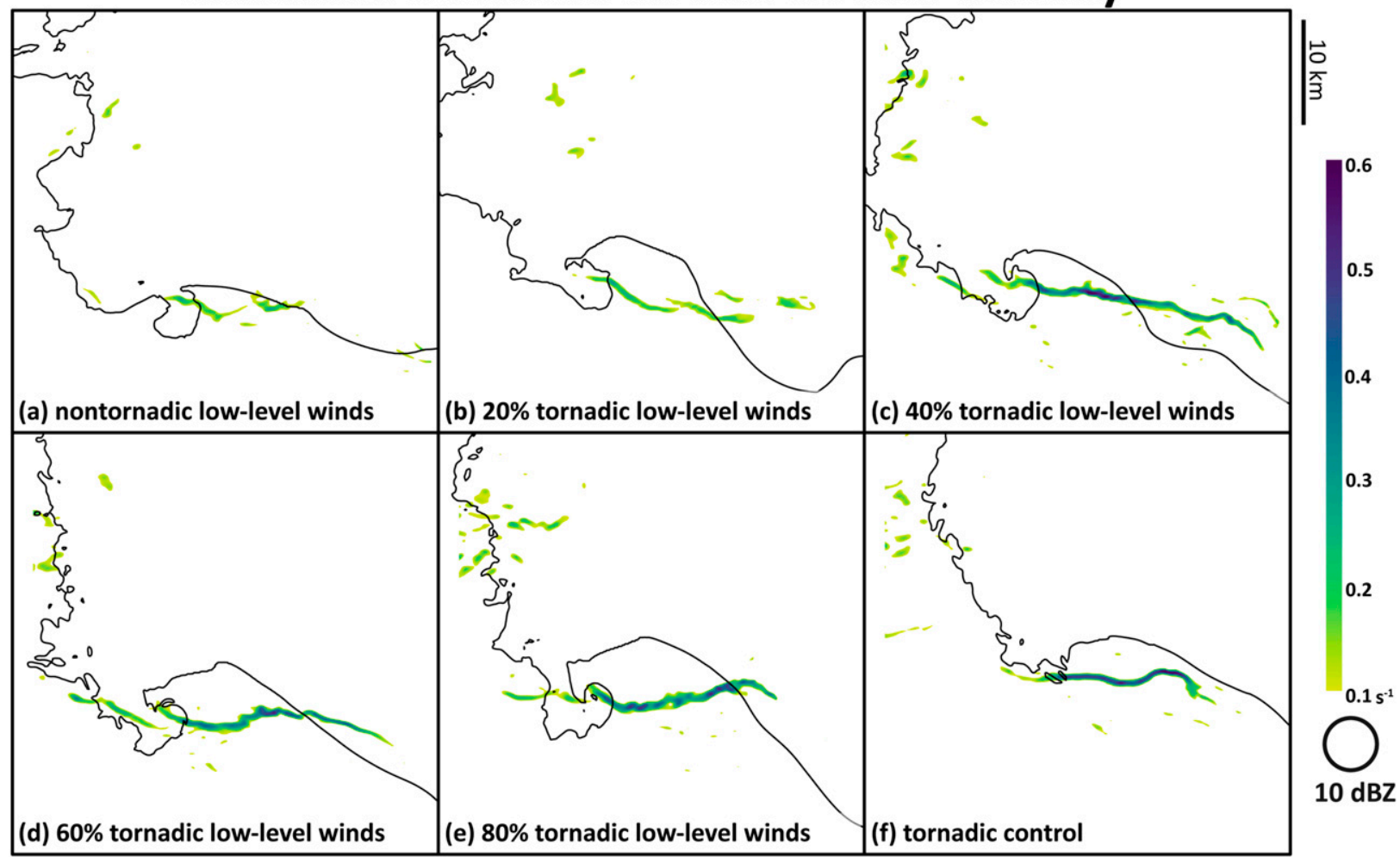

FIG. 3. Horizontal cross sections of $10 \mathrm{~m}$ AGL translated maximum vertical vorticity $\left(\mathrm{s}^{-1}\right.$; shaded) at the key time period of tornadogenesis or tornadogenesis failure for the tornadic VORTEX2 interpolated simulations. The 10-dBZ reflectivity contour (black) at $10 \mathrm{~m}$ AGL for the respective simulations is shown for reference. Refer to Table 2 for the key time period for each simulation.

using the nontornadic VORTEX2 environment produced weak tornadoes). However, all 15 of the ensemble members using the tornadic VORTEX2 environment produced long-track intense tornadoes, despite notable differences in the distribution of precipitation, the intensity and location of downdrafts, and the magnitude of near-surface buoyancy. This implies that the prevailing environment still exhibits very strong control over whether a tornado ultimately forms in favorable environments, but chaotic within-storm details can play a role and occasionally lead to marginally tornadic vortices in suboptimal storms.

However, true "cause and effect" remains elusive because there are still a number of unknown physical links that determine whether tornadogenesis succeeds or fails. As shown in $\mathrm{C} 17 \mathrm{~b}$, it is difficult to isolate the roles of the individual environmental ingredients directly upon tornadogenesis because the overall storm structures change in response to surprisingly small modifications of the environmental profile. The ranges of 0-500-m SRH values produced by the random $2 \mathrm{~m} \mathrm{~s}^{-1}$ wind perturbations in the VORTEX2 ensembles from $\mathrm{C} 17 \mathrm{~b}$ were $60-96$ and $138-174 \mathrm{~m}^{2} \mathrm{~s}^{-2}$ for the nontornadic and tornadic environments, respectively (Table 2 from C17b). Thus, the two populations did not overlap. Furthermore, these ranges were not broad enough to reveal a clear "tipping point" 3 between nontornadic and tornadic supercells in the nontornadic and tornadic VORTEX2 composite profiles. In fact, there was no correlation between the $0-500-\mathrm{m}$ SRH and maximum

\footnotetext{
${ }^{3}$ Although it is somewhat simplistic to expect there to be clear thresholds separating nontornadic from tornadic supercells, remarkable forecasting progress has been achieved in the past decade by treating severe weather as a probabilistic forecasting problem. The concept of a tipping point (i.e., threshold) for severe weather is widely prevalent in this operational application. For example, $0-1 \mathrm{~km}$ AGL SRH $>100 \mathrm{~m}^{2} \mathrm{~s}^{-2}$ suggests a threat for tornadic supercells (Thompson et al. 2003), and a significant tornado parameter (STP) $>1$ is associated with a majority of tornadoes F2 or greater in damage, while most nontornadic supercells are associated with STP $<1$ (Thompson et al. 2012).
} 


\section{Tornadic VORTEX2 interpolated simulations: Density potential temperature perturbation}

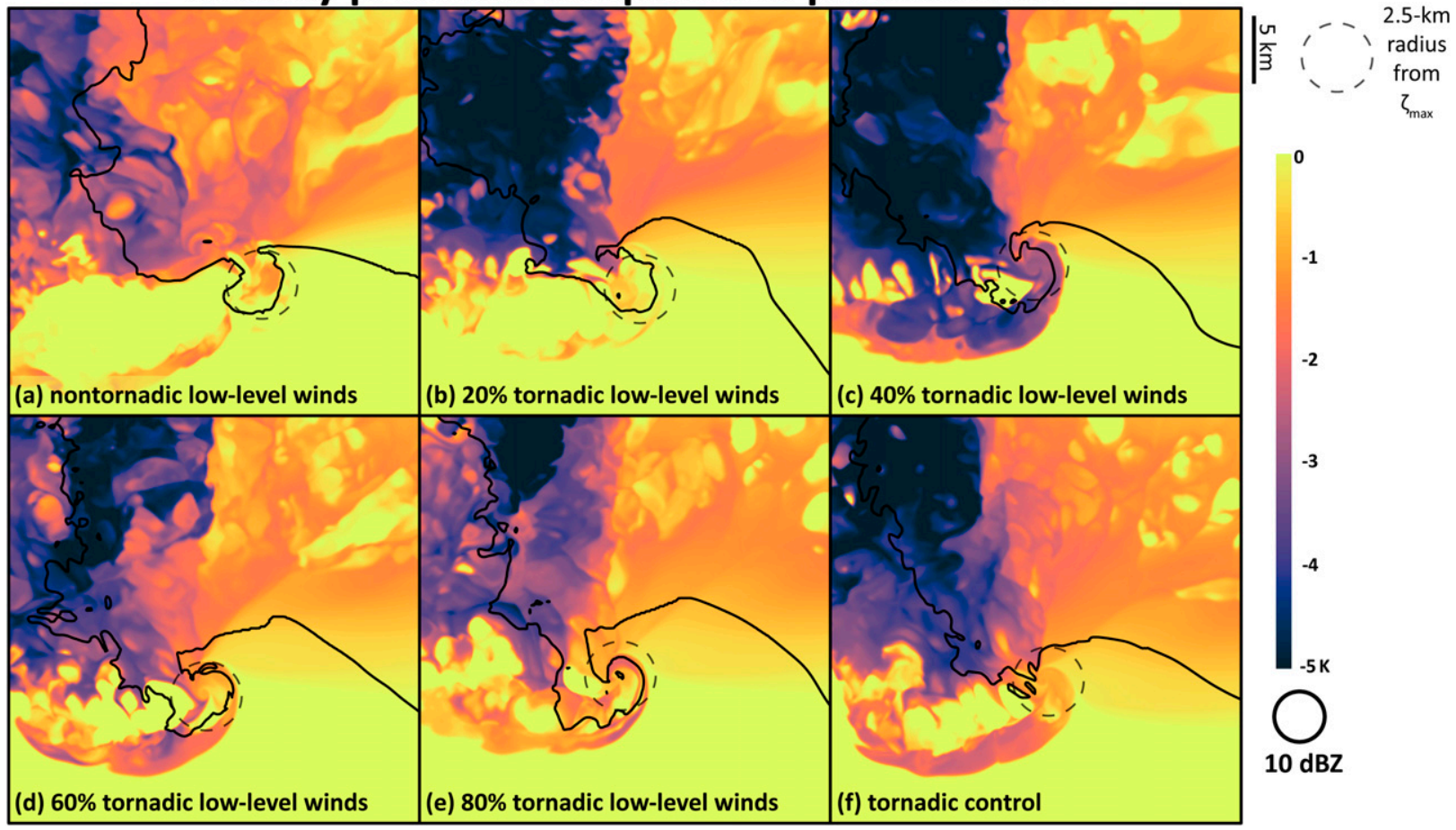

FIG. 4. Horizontal cross sections of $10 \mathrm{~m}$ AGL density potential temperature perturbation (K; shaded) at the key time period of tornadogenesis or tornadogenesis failure for the tornadic VORTEX2 interpolated simulations. The 10-dBZ reflectivity contour (black) at $10 \mathrm{~m}$ AGL for the respective simulations is shown for reference. Refer to Table 2 for the key time period for each simulation. The dashed circle in each panel encloses the 2.5 -km-radius ring around the surface vertical vorticity maximum at the key time period used in Figs. 5 and 8.

surface vertical vorticity within either the nontornadic or tornadic VORTEX2 ensembles. This suggests that if there is a critical value of lower-tropospheric SRH that heavily favors tornadic supercells within the VORTEX2 composite parameter space, the $\mathrm{C} 17 \mathrm{~b}$ simulations did not identify it.

One possibility is that a tipping point exists but falls between the two populations that $\mathrm{C} 17 \mathrm{~b}$ previously tested. If a tipping point were to exist, it is also possible that SRH is not the most relevant quantity to consider. Perhaps it is important to consider the magnitude of streamwise versus crosswise horizontal vorticity (or even a ratio of the two components). Along these lines, $\mathrm{C} 17 \mathrm{a}, \mathrm{b}$ found that the orientation of the environmental horizontal vorticity influences the organization of the low-level mesocyclone, where predominately crosswise horizontal vorticity leads to strikingly disorganized low-level mesocyclones. Considering that all of the ensemble members from $\mathrm{C} 17 \mathrm{~b}$ produced tornadoes in the tornadic VORTEX2 composite environment, it is unclear what amount of near-surface crosswise horizontal vorticity is necessary to disrupt the low-level mesocyclone sufficiently for tornadogenesis failure.

In the present work, we progressively vary all three of these ingredients (SRH and streamwise and crosswise vorticity) in a first attempt to clarify whether there is an obvious transition in behavior. How much would the tornadic VORTEX2 environment need to be perturbed in order to disrupt what is apparently a very high intrinsic probability for tornadogenesis? Or, on the other hand, how much would the nontornadic VORTEX2 environment need to be "improved" in order for a substantial probability of tornadogenesis to emerge?

The primary scientific question we seek to address herein is whether tornadogenesis within the parameter space encompassed by the VORTEX2 composite environments is most sensitive to the lower-tropospheric wind profile, the upper-tropospheric wind profile, or the thermodynamic profile. Additional simulations beyond the $\mathrm{C} 17 \mathrm{a}, \mathrm{b}$ studies have therefore been conducted where the environment is systematically varied between the nontornadic and tornadic VORTEX2 composite profiles 


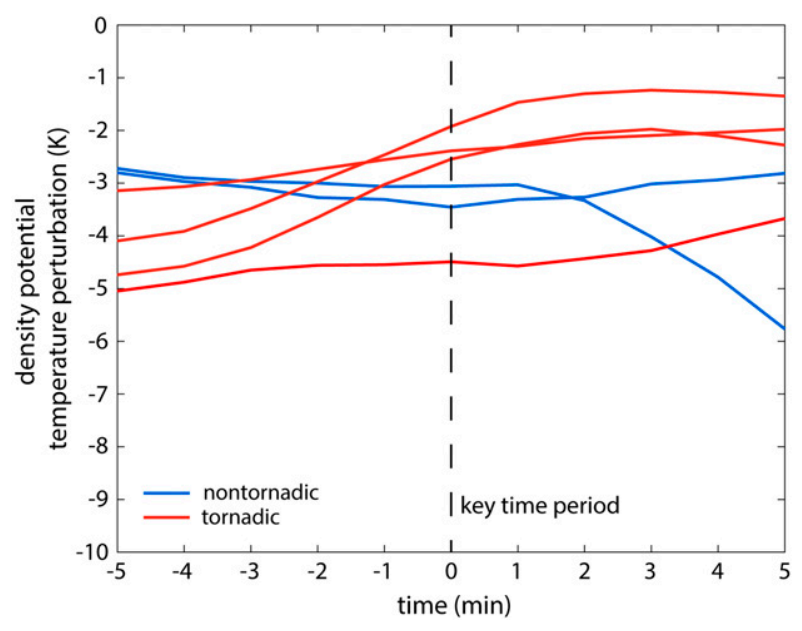

FIG. 5. Time series comparing the minimum density potential temperature perturbation within a $2.5-\mathrm{km}$ radius of the surface vertical vorticity maximum for the tornadic VORTEX2 interpolated simulations within a 10-min period centered on the key time period. Refer to Table 2 for a list of which simulations are tornadic or not. A five-point smoother was used on each time series to account for jumps while tracking the supercell's surface vertical vorticity maximum.

(Fig. 1). The initial conditions for one set of these variations use the thermodynamic profile and upper-level winds from the tornadic VORTEX2 composite, and the other uses the thermodynamic profile and upper-level winds from the nontornadic VORTEX2 composite. The low-level wind (LLW) profiles are linearly interpolated between the two composites $(20 \%, 40 \%, 60 \%$, and $80 \%$ ), as shown in Fig. 1. As illustrated in C17a,b, the environmental streamwise vorticity in the lowest $500-1000 \mathrm{~m}$ AGL is of primary importance to accomplishing the stretching needed for "stage 3" of tornado production (Davies-Jones 2015). By holding all other factors fixed and varying only the low-level wind profile, the impacts of the near-ground streamwise vorticity can be isolated from any effects associated with CAPE, humidity, and upper-level flow.

Moreover, one aspect omitted from $\mathrm{C} 17 \mathrm{a}, \mathrm{b}$ was that subtle differences in the thermodynamic profile between the nontornadic and tornadic VORTEX2 composites (e.g., more CAPE, less CIN, and higher boundary layer humidity in the tornadic VORTEX2 environment) were not fully explored, and the tornadogenesis outcome could be sensitive to these differences. Therefore, simulations were also performed "swapping" the thermodynamic profile between the nontornadic and tornadic VORTEX2 composites in order to further isolate the role of the low-level wind profile upon tornado production.

Section 2 reviews the numerical setup of the simulations performed herein. Results of the interpolated low-level wind profile simulations, followed by the thermodynamic profile sensitivity tests, are presented in section 3. A discussion of the implications and avenues for future work are offered in section 4 .

\section{Methods}

The simulations herein used release 18 of Cloud Model version 1 [CM1; Bryan et al. (2003); also see appendix of Bryan and Morrison (2012)]. The model setup is the same as $\mathrm{C} 17 \mathrm{~b}$ and is summarized in Table 1. Highlights include 125-m horizontal grid spacing, 115 vertical levels (including 31 levels in the lowest kilometer), double-moment NSSL microphysics, and a semislip bottom boundary condition (discussed in more detail in section $2 b$ of $\mathrm{C} 17 \mathrm{a}$ ).

In total, 20 simulations were performed, including five simulations for each of the nontornadic and tornadic VORTEX2 interpolated environments (Table 2). The interpolated suite of simulations based on the tornadic VORTEX2 environment consists of one simulation with the nontornadic lower-tropospheric winds (with everything else from the tornadic VORTEX2 environment) and four simulations with lower-tropospheric wind profiles interpolated between the two composite environments at $20 \%$ intervals (Fig. 1, Table 2). The inverse procedure is then performed with the nontornadic VORTEX2 environment. This kind of controlled experiment is possible because (serendipitously) the winds at approximately $2.5 \mathrm{~km}$ AGL are almost identical in the nontornadic and tornadic composites. Finally, a thermodynamic profile sensitivity test is performed by swapping the thermodynamic profile between the nontornadic and tornadic VORTEX2 composites, keeping the entire wind profile the same as in the original VORTEX2 composite environments. These additional sensitivity tests were then compared to the control members of the VORTEX2 ensembles in C17b (e.g., their Figs. 3-8a, 10-15a) using similar analysis techniques as in C17a,b.

Each of the interpolated simulations was given an acronym that describes the environmental initial conditions (Table 2). The first characters refer to the upper-level winds and thermodynamic profile used (i.e., "torV2" will describe the interpolated simulations based on the tornadic VORTEX2 environment). The characters following the hyphen specify the low-level wind profile employed. The full nontornadic (tornadic) low-level wind profile is referred to as "ntLLW" (torLLW). The interpolated lowlevel profiles are then labeled by the appropriate $20 \%$ interval. For example, the "torV2-40torLLW" (i.e., $40 \%$ tornadic low-level winds) simulation uses the tornadic VORTEX2 composite thermodynamic profile and upper-level winds, with a low-level wind profile that is 


\section{Tornadic VORTEX2 interpolated simulations:} $1 \mathrm{~km}$ vertical velocity

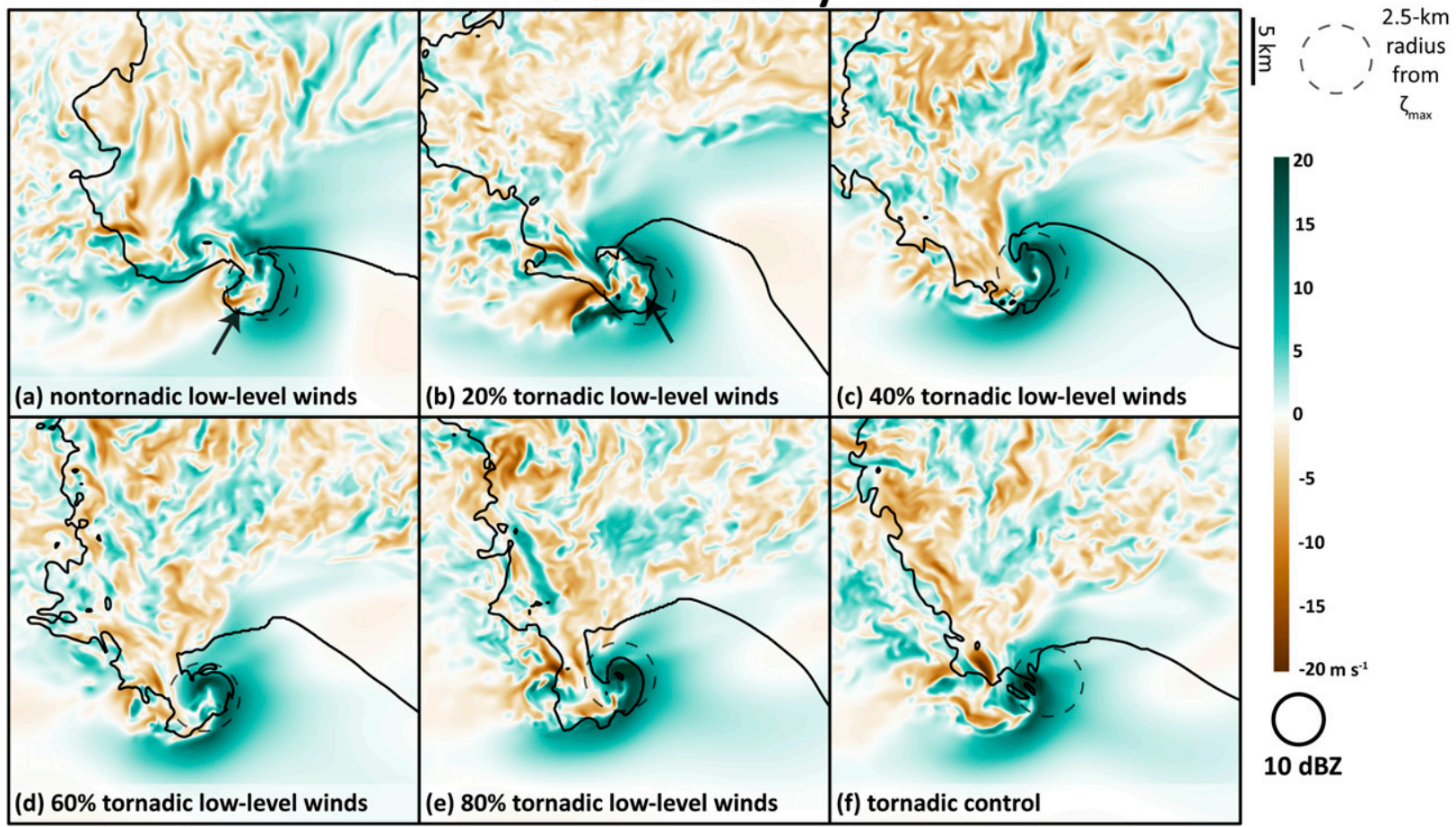

FIG. 6. Horizontal cross sections of $1 \mathrm{~km} \mathrm{AGL} \mathrm{vertical} \mathrm{velocity}\left(\mathrm{m} \mathrm{s}^{-1}\right.$; shaded) at the key time period of tornadogenesis or tornadogenesis failure for the tornadic VORTEX2 interpolated simulations. The 10-dBZ reflectivity contour (black) at $10 \mathrm{~m}$ AGL for the respective simulations is shown for reference. Refer to Table 2 for the key time period for each simulation. The dashed circle in each panel encloses the 2.5-km-radius ring around the surface vertical vorticity maximum at the key time period used in Figs. 5 and 8 . The black arrows point to pockets of descent, evidence of a disorganized low-level updraft, referenced in the text.

$40 \%$ of the way between the nontornadic and tornadic composites (i.e., closer to the nontornadic low-level wind profile). Last, the "control" simulations are the unmodified VORTEX2 composite profiles, which were discussed in $\mathrm{C} 17 \mathrm{~b}$.

Each run will subsequently be described as tornadic, weakly tornadic, or nontornadic based on whether the supercell meets the tornadogenesis criteria outlined in section 2 of $\mathrm{C} 17 \mathrm{~b}$, which, for completeness, are restated here. A key time period of tornadogenesis or tornadogenesis failure was chosen based on several subjectively determined thresholds. Tornadogenesis was said to occur whenever all of the following criteria were met: 1 ) the surface vertical vorticity exceeds $0.3 \mathrm{~s}^{-1}, 2$ ) the pressure deficit (relative to the base-state environmental sounding) within the vortex exceeds $10 \mathrm{hPa}$ over a depth of at least $1 \mathrm{~km}$, and 3) the instantaneous ground-relative wind speed exceeds $35 \mathrm{~m} \mathrm{~s}^{-1}$ ( $\sim 78 \mathrm{mph}$, midrange EF0 wind speeds) at $10 \mathrm{~m}$ AGL. All criteria needed to be simultaneously present for at least $2 \mathrm{~min}$. If a supercell did not meet the tornadogenesis criteria at any point during the entire simulation, tornadogenesis failure was said to occur at the time of maximum surface vertical vorticity after the storm reached maturity.

We discuss these additional simulations in the following subsections, first for the interpolated simulations based on the tornadic VORTEX2 thermodynamic profile and upper-level winds (torV2-*; section 3a) and then for interpolated simulations based on the nontornadic VORTEX2 thermodynamic profile and upper-level winds (ntV2-*; section $3 b$ ). Finally, the thermodynamic sensitivity tests are presented in section $3 \mathrm{~d}$.

\section{Results}

a. Characteristics of the interpolated simulations based on the tornadic VORTEX2 environment

In this suite of six simulations, the initial conditions consist of the thermodynamic profile and upper-level winds from the tornadic VORTEX2 composite, while the low-level wind profile varies (Table 2, Fig. 1). One simulation possesses the nontornadic VORTEX2 


\section{Tornadic VORTEX 2 interpolated simulations:}
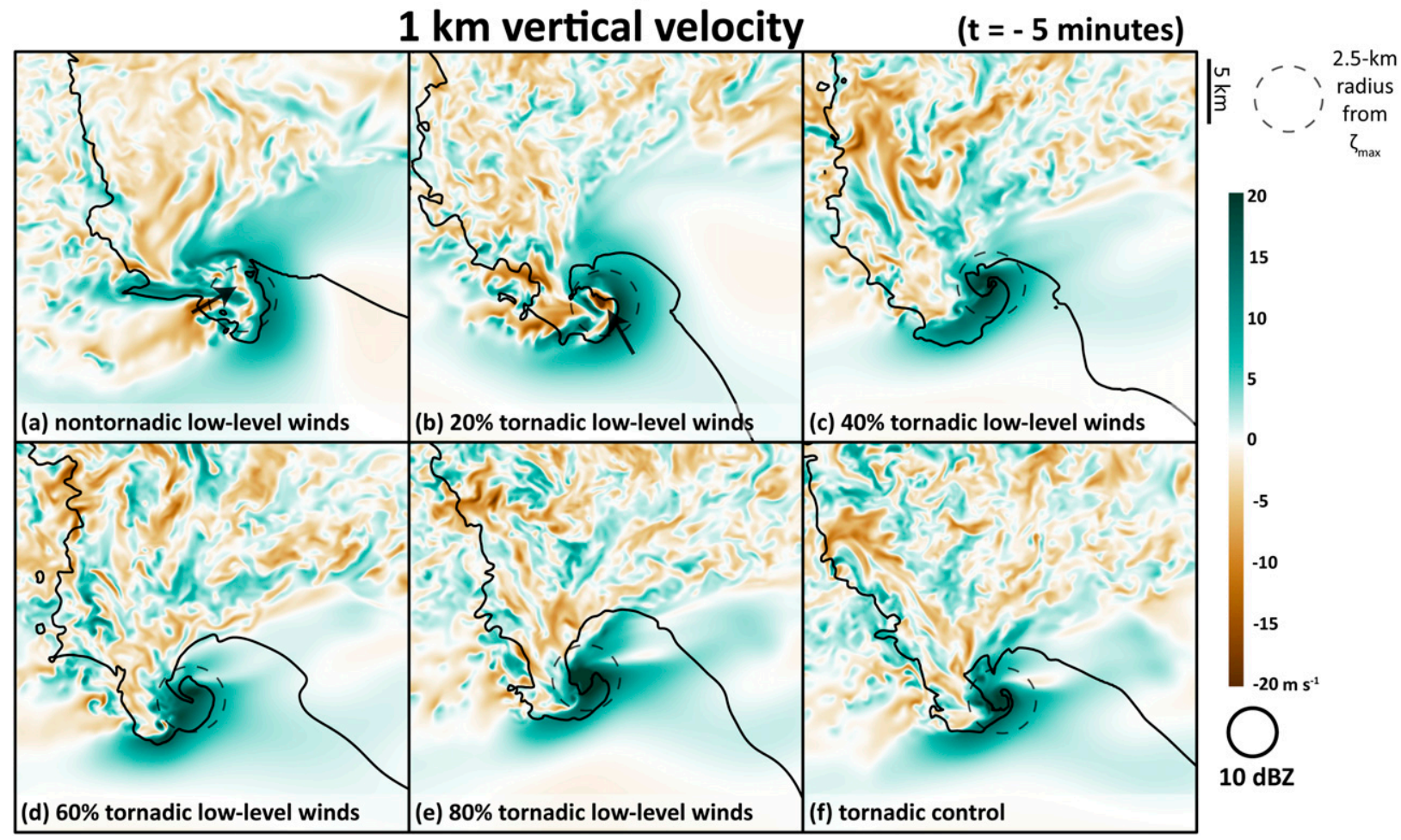

FIG. 7. As in Fig. 6, but for 5 min before the key time period.

low-level wind profile (i.e., torV2-ntLLW simulation; Table 2, Fig. 1). The ensuing four simulations have a low-level wind profile linearly interpolated between the nontornadic and tornadic VORTEX2 composite environments at $20 \%$ intervals (e.g., torV2-20torLLW simulation; Table 2, Fig. 1). The torV2-control simulation is the same as in $\mathrm{C} 17 \mathrm{~b}$.

A dominant, cyclonic supercell is apparent in each of the six tornadic VORTEX2 interpolated simulations by approximately $45 \mathrm{~min}$ into the simulations. Each of the storms looks rather similar when examining the reflectivity field (Fig. 2), with perhaps the exception of the torV2-ntLLW simulation, which has high values of reflectivity in the far rear of the storm (Fig. 2a). Each storm has a hook echo appendage. Despite this, both the torV2-ntLLW (Fig. 3a) and the torV2-20torLLW (Fig. 3b) simulations are nontornadic. The supercell in the torV2-20torLLW simulation has a marginally intense swath of vertical vorticity exceeding $0.2 \mathrm{~s}^{-1}$ for approximately $10 \mathrm{~km}$ (Fig. 3b), but its maximum vertical vorticity and pressure falls never continuously meet the minimum definition of a tornado used in this study (not shown). It is possible, in nature, that such swaths of vertical vorticity would be considered tornadic. Even so, there is a clear regime change from the $20 \%$ to $40 \%$ tornadic low-level winds simulations, especially when the swaths of maximum pressure deficits and wind speeds (as well as the three-dimensional structure of vertical vorticity and pressure deficits) are considered. The intensity of the tornadic vortices is significantly enhanced once the lower-tropospheric wind profile incorporates at least $40 \%$ of the structure from the tornadic VORTEX2 composite (Figs. $3 \mathrm{c}-\mathrm{f}$ ), ${ }^{4}$ indicating that the tornadogenesis process within the VORTEX2 composite environments is most sensitive to the lower-tropospheric wind profile, irrespective of the upper-tropospheric winds or thermodynamic profile.

The transition in tornadic intensity from $20 \%$ to $40 \%$ cannot be attributed to warmer outflow temperatures in the tornadic storms (Fig. 4). Previous studies have concluded that colder outflow temperatures tend to inhibit

\footnotetext{
${ }^{4}$ The fact that the tornado pathlength for the tornadic control simulation is shorter than the other tornado pathlengths in the $40 \%, 60 \%$, and $80 \%$ simulations is circumstantial. In $\mathrm{C} 17 \mathrm{~b}$, the control simulation happened to be on the lower end of the 15-member ensemble's pathlength distribution $(\sim 15-30 \mathrm{~km})$. The other three simulations have pathlengths that are closer to the median pathlength from $\mathrm{C} 17 \mathrm{~b}$.
} 


\section{Tornadic VORTEX2 interpolated simulations: $1 \mathrm{~km}$ vertical velocity distribution}

nontornadic low-level winds

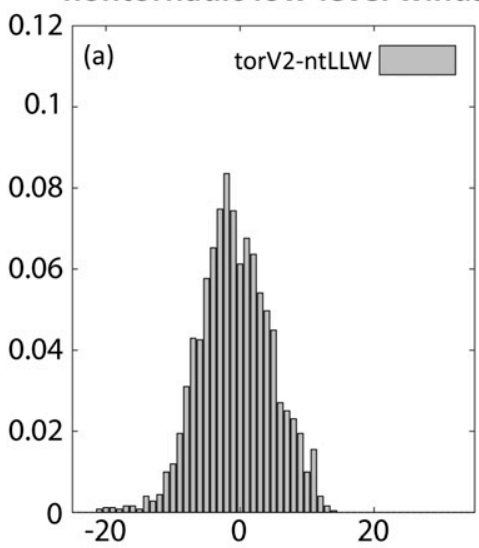

$60 \%$ tornadic low-level winds

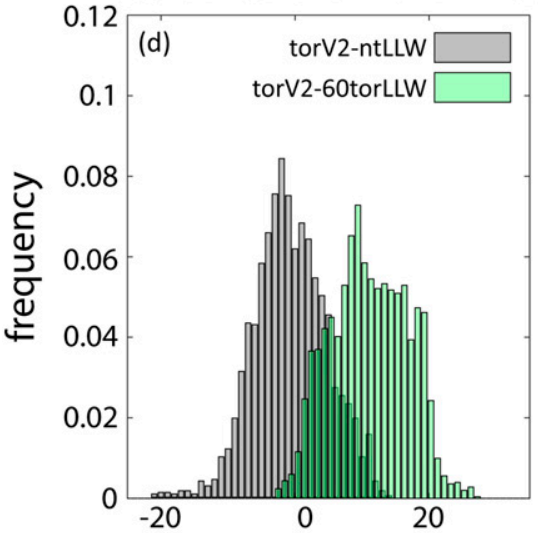

$20 \%$ tornadic low-level winds

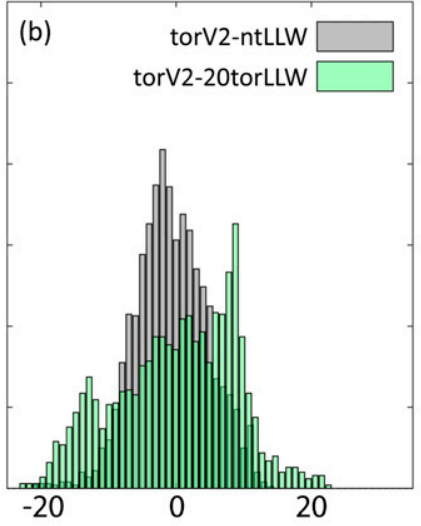

$80 \%$ tornadic low-level winds

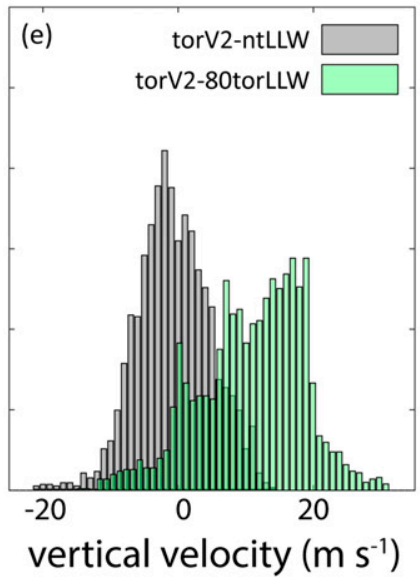

$40 \%$ tornadic low-level winds

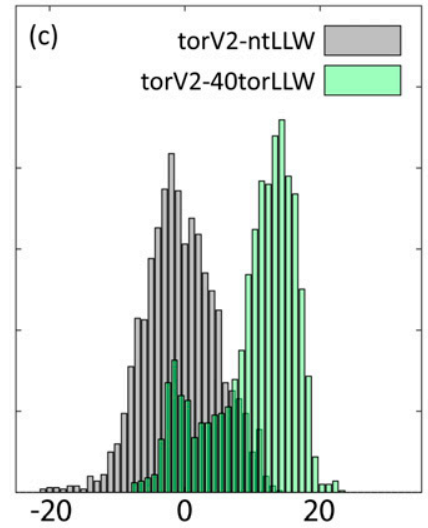

tornadic control

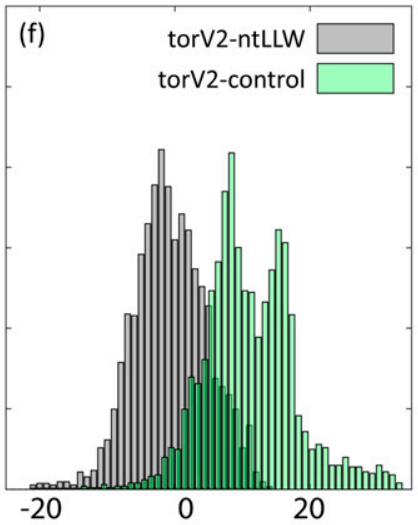

FIG. 8. Frequency histograms of vertical velocity grid points at $1 \mathrm{~km}$ AGL within a $2.5-\mathrm{km}$ radius of the surface vertical vorticity maximum during the $5 \mathrm{~min}$ preceding the key time period of tornadogenesis or tornadogenesis failure for the tornadic VORTEX2 interpolated simulations. In (b)-(f) the histogram for nontornadic LLW simulation (torV2-ntLWW) is shown for comparison. Restricting the area of analysis to a $1-\mathrm{km}$ radius did not appreciably change the result.

tornadogenesis (e.g., Markowski et al. 2002). All six storms herein have relatively weak cold pools in the vicinity of the surface circulation throughout most of a 10-min time span centered on the key time period (Fig. 5). The most negatively buoyant air within a $2.5-\mathrm{km}$ radius of the surface vertical vorticity maximum ranges from approximately -2 to $-5 \mathrm{~K}$ (Fig. 5). Using a smaller radius from the surface vertical vorticity maximum did not result in significant differences between nontornadic and tornadic storms (not shown).

Compared to observations, the cold pools in this series of studies are comparatively warm. In the 30 supercells sampled during the first VORTEX field project by
Markowski et al. (2002), potential temperature perturbations warmer than $-2 \mathrm{~K}$ were fairly rare. Perhaps the interactions among the microphysics scheme, the subgridscale turbulence scheme, and/or the bottom boundary condition (the inclusion of drag leads to stronger near-surface turbulent mixing within the outflow; e.g., Markowski 2016) produce cold pools that are systematically too warm and without enough spread. Furthermore, pockets of warm outflow within the rear-flank region are more prevalent in these simulations than other studies. Areas of positive potential temperature perturbation do appear in other recent high-resolution simulations ; of tornadogenesis [e.g., Honda and Kawano (2016), their Fig. 3b; Schenkman et al. (2016), their Fig. 4; 


\section{Tornadic VORTEX2 interpolated simulations: $1 \mathrm{~km}$ circulation}

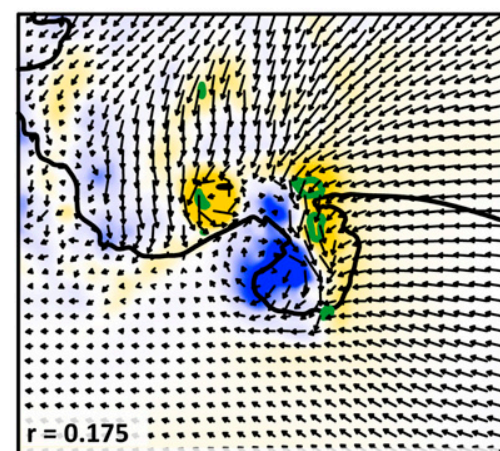

(a) nontornadic low-level winds

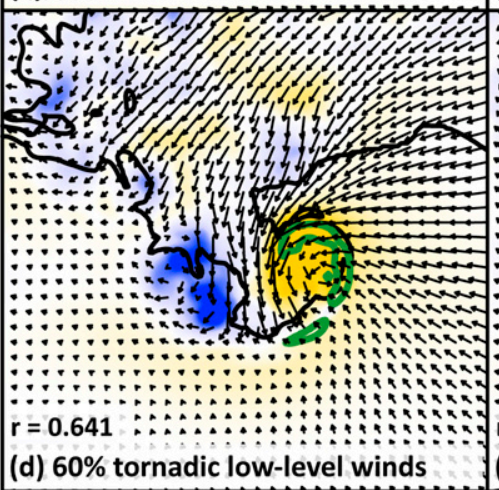

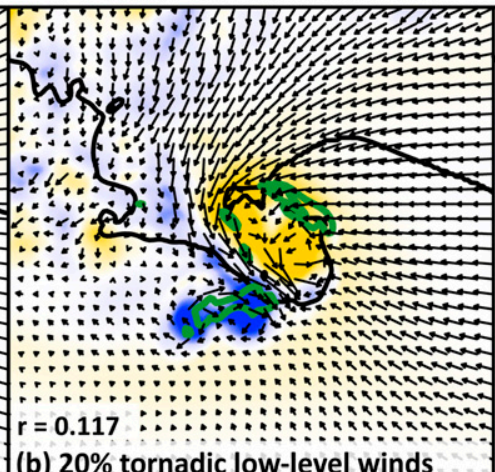

(b) $20 \%$ tornadic low-level winds

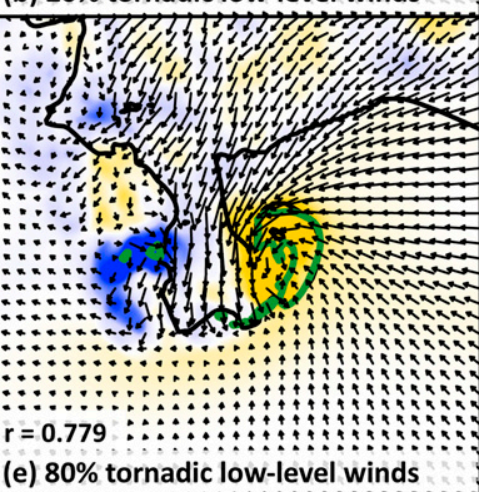

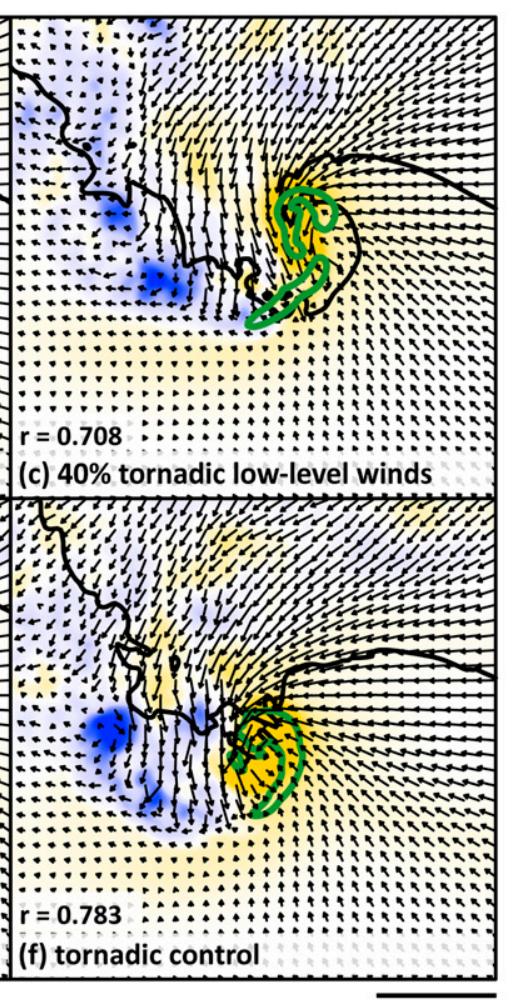

$5 \mathrm{~km}$

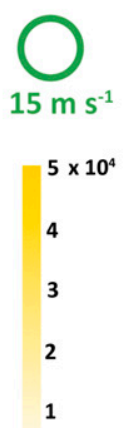

1

0

$-1$

$-2$

$-3$

$-4$

$-5 \times 10^{4}$ $\mathrm{m}^{2} \mathrm{~s}^{-1}$

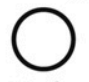

$10 \mathrm{dBZ}$

FIG. 9. Horizontal cross sections of $1 \mathrm{~km}$ AGL circulation $\left(\mathrm{m}^{2} \mathrm{~s}^{-1}\right.$; shaded $)$ at the key time period of tornadogenesis or tornadogenesis failure for the tornadic VORTEX2 interpolated simulations. Circulation was computed within a 1-km-radius horizontal ring centered on each grid point within the domain's constant grid spacing inner mesh. The spatial correlation $r$ between updraft and the circulation field at $1 \mathrm{~km}$ AGL was calculated for each member. The $10-\mathrm{dB} Z$ reflectivity contour (black) at $10 \mathrm{~m}$ AGL and the $15 \mathrm{~m} \mathrm{~s}^{-1}$ vertical velocity contour (green) at $1 \mathrm{~km}$ AGL for the respective simulations are shown for reference. Vectors represent the perturbation horizontal velocity, plotting every fifth vector. Refer to Table 2 for the key time period for each simulation. See also Fig. S2 for an animated version of this figure.

Orf et al. (2017), their Fig. 11], as well as in observations using novel observing platforms [Weiss et al. (2015), their Fig. 5b; Riganti and Houston (2017), their Fig. 17]. In the supercells studied by $\mathrm{C} 17 \mathrm{a}, \mathrm{b}$ and herein, areas of positive potential temperature perturbation primarily coincide with high concentrations of small drops (not shown). Conceivably, this process could be similar to that discussed in Kumjian (2011), Kumjian et al. (2015), French et al. (2015), and Schenkman et al. (2016), where numerous warm rain-generated droplets are dynamically forced downward faster than their normal fall velocity due to stagnating low-level air on the upshear side of the hook echo. Regardless, as will be shown next, the conclusions seem mostly immune to these uncertainties in the thermodynamics, as the low-level updraft organization, intensity, and steadiness are robustly tied to details of the low-level hodograph.
While vertical velocities exceeding $15 \mathrm{~m} \mathrm{~s}^{-1}$ are present at $1 \mathrm{~km}$ in both nontornadic supercells (Figs. 6a,b), the low-level updraft is generally disorganized, spatially more diffuse, and overall weaker, compared to the tornadic supercells' $1-\mathrm{km}$ updrafts (Figs. 6c-f), with pockets of descent present where the surface vertical vorticity resides (near and adjacent to the rear-flank precipitation). In this context, "disorganization" of the low-level updraft refers to spatially incoherent updraft/downdraft structures with strong areas of descent immediately adjacent to areas of updraft in close spatial proximity to the rearflank precipitation (see arrows in Figs. 6 and 7, and 13 for examples of disorganized low-level updrafts). It should not be inferred that downdrafts are necessarily bad for tornadoes. There is a well-established connection between downdrafts (and the corresponding low-level baroclinity) with the source of pretornadic vertical vorticity 


\section{Tornadic VORTEX2 interpolated simulations:}
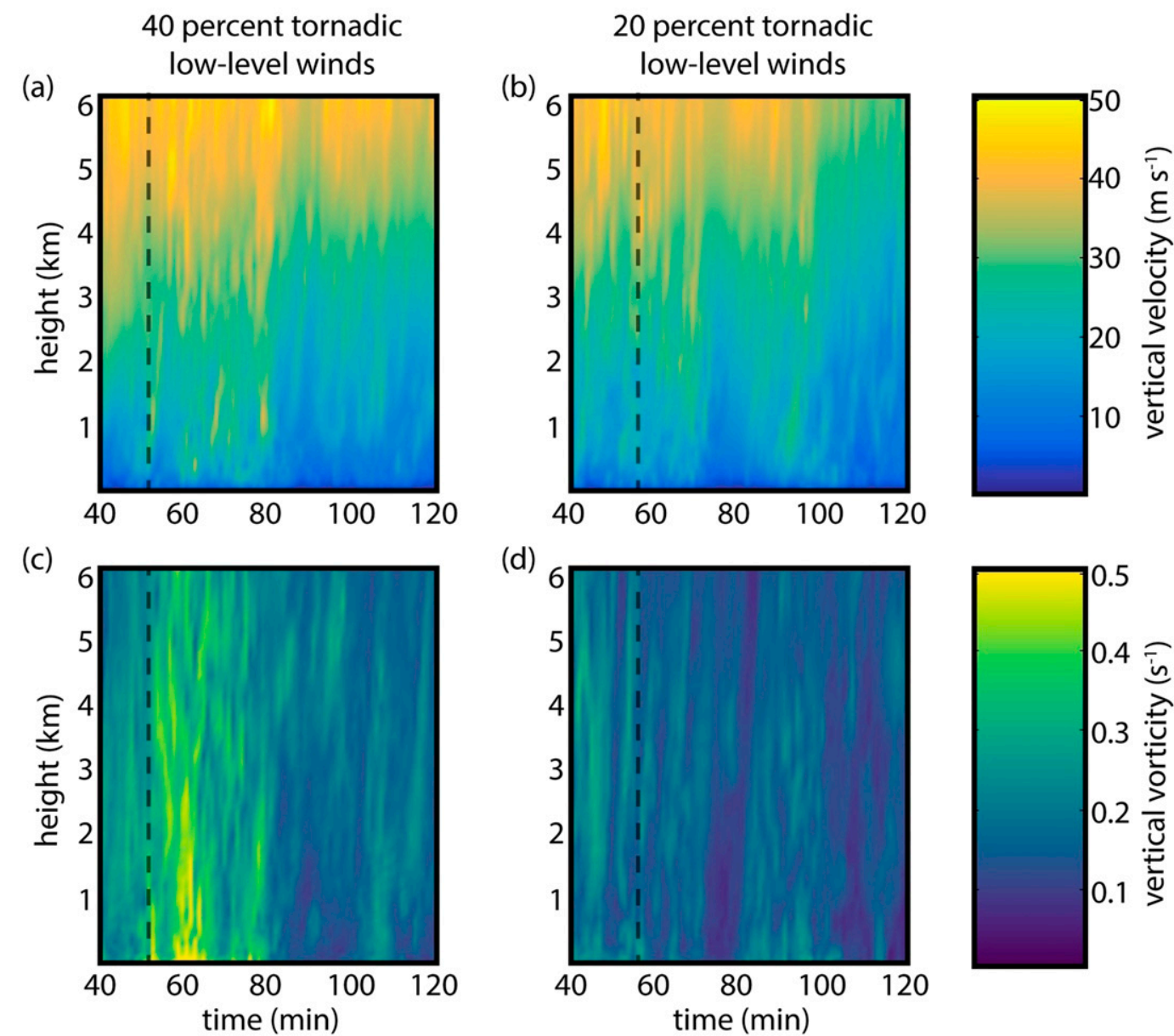

(d)
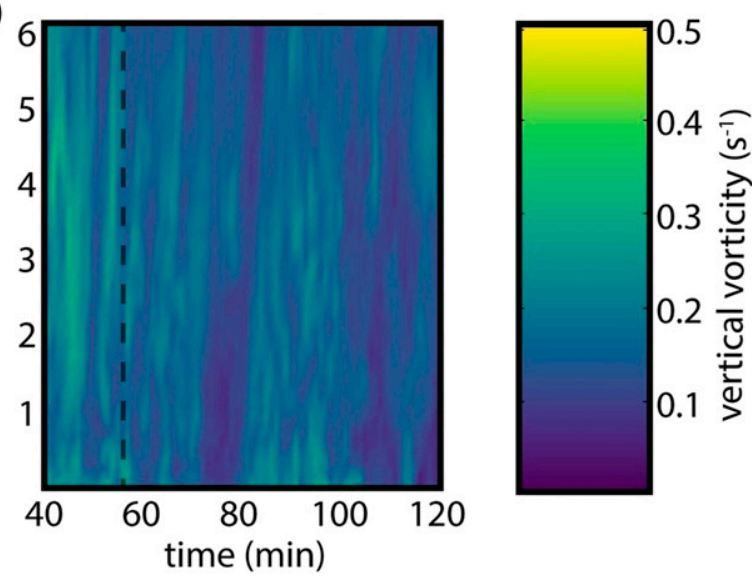

FIG. 10. Time-height plot of maximum (top) vertical velocity $\left(\mathrm{m} \mathrm{s}^{-1}\right)$ and (bottom) vertical vorticity $\left(\mathrm{s}^{-1}\right)$ in a $50-\mathrm{km}^{2}$ box following the midlevel mesocyclone for the (left) $40 \%$ and (right) $20 \%$ tornadic LLW simulations from the tornadic VORTEX2 interpolated suite of simulations. The dashed black line indicates the key time period of tornadogenesis or tornadogenesis failure for each simulation (Table 2).

at the surface (e.g., Davies-Jones and Brooks 1993; Markowski et al. 2008; Markowski and Richardson 2014; Dahl et al. 2014; Parker and Dahl 2015). However, convergence and stretching (and thus updraft) are required in order to transition from a pretornadic vortex to a tornadic-strength vortex. Depending on the rate of convergence, the radius of the initial pretornadic vortex, and the maximum tangential velocity, this process likely takes anywhere from 5 to $15 \mathrm{~min}$ (Davies-Jones et al. 2001). This requires an organized, intense, and steady low-level updraft. During the $5 \mathrm{~min}$ preceding tornadogenesis, the two nontornadic supercells exhibit frequent areas of weak vertical velocities or even areas of strong descent directly overlying the developing near-surface vortices (Figs. 8a,b).
In contrast, at the time of tornadogenesis, all four of the tornadic supercells have a broad area of intense low-level updraft directly within the rearflank precipitation and developing near-surface rotation (Figs. 6c-f). Each of the tornadoes originates underneath this intense region of low-level updraft (cf. Figs. 3c-f with Figs. 6 c-f, 7c-f). Quantitatively, compared to the two nontornadic supercells, the tornadic supercells have stronger updrafts and much fewer downdraft grid points in the vicinity of the developing near-surface vortices (Figs. $8 \mathrm{c}-\mathrm{f}$ ). Just as in every simulation previously shown in $\mathrm{C} 17 \mathrm{a}, \mathrm{b}$, there is ample subtornadic surface vertical vorticity available to be stretched (Fig. S1 in the online supplemental material), but without a persistent area of upward lifting, the surface vertical vorticity that does develop 
Tornadic VORTEX2 interpolated: $40 \%$ tornadic low-level winds

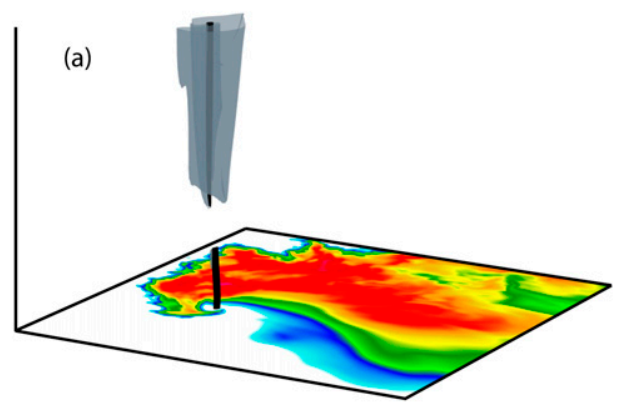

Nontornadic VORTEX2 interpolated: $80 \%$ tornadic low-level winds

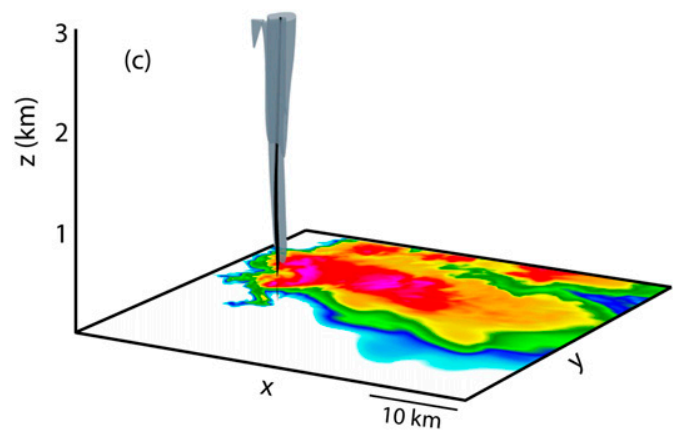

$20 \mathrm{~m} \mathrm{~s}^{-1}$ updraft isosurface

$0.01 \mathrm{~s}^{-2}$ Okubo-Weiss isosurface
Tornadic VORTEX2 interpolated: $20 \%$ tornadic low-level winds

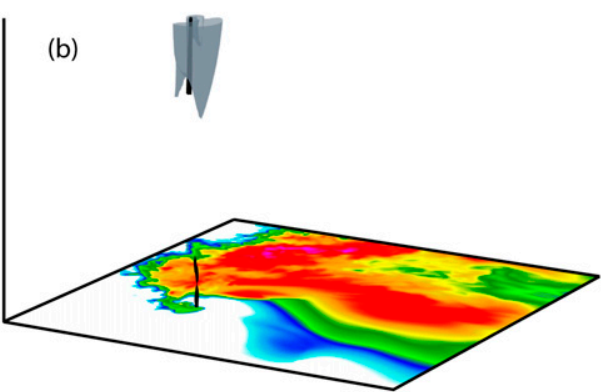

Nontornadic VORTEX2 interpolated: $20 \%$ tornadic low-level winds
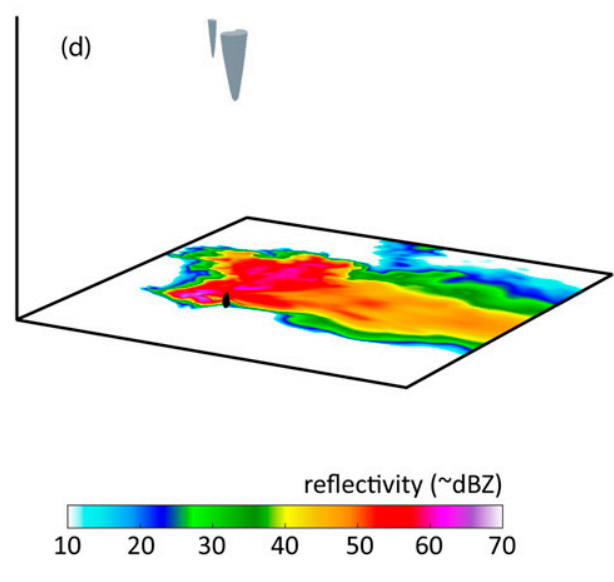

FIG. 11. Three-dimensional view of the low-level mesocyclone and potentially tornadic vortices for various interpolated VORTEX2 simulations at 5 min prior to the key time period of tornadogenesis or tornadogenesis failure. Refer to Table 2 for the key time period for each simulation. Shaded on the surface is the $10 \mathrm{~m}$ AGL reflectivity $(\sim \mathrm{dBZ})$. Updraft and Okubo-Weiss isosurfaces of $20 \mathrm{~m} \mathrm{~s}^{-1}$ and $0.01 \mathrm{~s}^{-2}$ are shown in light gray and black, respectively. Herein, the Okubo-Weiss parameter is defined as the square of the vertical vorticity $\zeta$ minus the square of the deformation $D\left(=\sqrt{D_{\text {stretching }}^{2}+D_{\text {shearing }}^{2}}\right)$ to highlight the rotation of the fluid (Okubo 1970; Weiss 1991). The vertical axis is exaggerated for plotting purposes.

in the nontornadic supercells is not likely to be contracted into a tornado.

An area of upward motion is a persistent feature of each of the tornadic supercells several minutes before tornadogenesis (Figs. $7 \mathrm{c}-\mathrm{f}, 8 \mathrm{c}-\mathrm{f}$ ). Since the pockets of downdraft are present where the surface vertical vorticity resides preceding the time of tornadogenesis failure (Figs. 7a,b, 8a,b), it is evident that the descent within and adjacent to the rear-flank precipitation in the nontornadic storms is not just a symptom of the downward dynamical vertical perturbation pressure gradient acceleration in response to intensifying near-surface rotation at the key time period. Rather, the downdraft signature is a recurring feature of the unsteady low-level mesocyclone due to the far-field environmental horizontal vorticity being predominately crosswise, as outlined in $\mathrm{C} 17 \mathrm{a}, \mathrm{b}$ and discussed further in the next paragraph.

As streamwise horizontal vorticity is increased in the lower troposphere, the low-level updraft not only becomes stronger, but also becomes increasingly superimposed with the low-level cyclonic circulation field (Fig. 9; also see Fig. S2 for an animated version of this figure). For the nontornadic supercells, the low-level cyclonic circulation couplet is primarily out of phase with the main updraft, a symptom of fluxing horizontal vorticity with a substantial crosswise component into and through the updraft (Davies-Jones 1984). The wind 


\section{Nontornadic VORTEX2 interpolated simulations: Reflectivity}

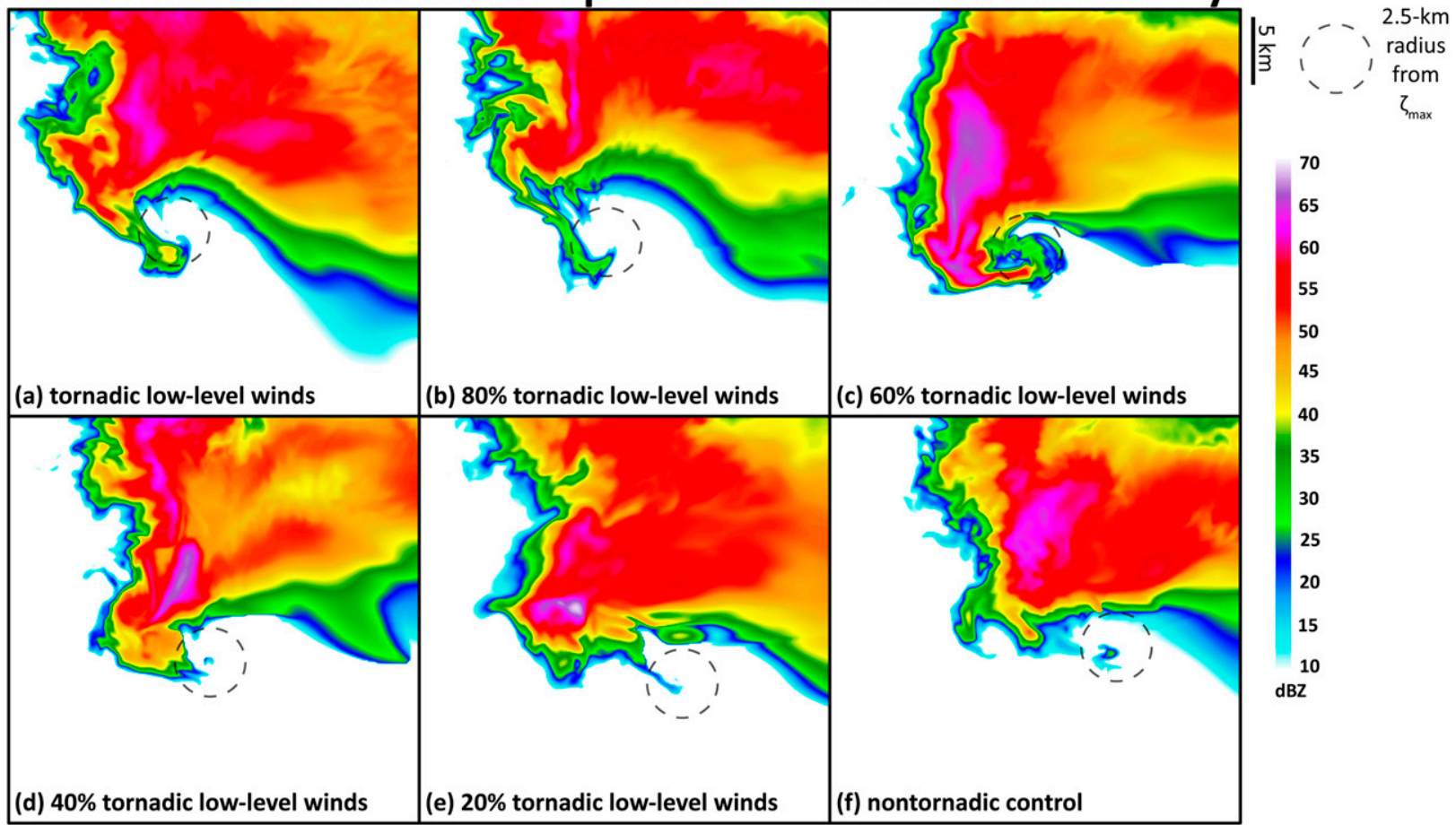

FIG. 12. As in Fig. 2, but for the nontornadic VORTEX2 interpolated simulations. Refer to Table 2 for the key time period for each simulation. The dashed circle in each panel encloses the $2.5-\mathrm{km}$-radius ring around the surface vertical vorticity maximum at the key time period used in Fig. 16.

field at $1 \mathrm{~km}$ AGL is associated with a deformational pattern, rather than a closed circulation (Figs. 9a,b). Since deformation is associated with locally positive nonlinear dynamic pressure perturbations, there are positive pressure perturbations at $1 \mathrm{~km}$ directly above the center of surface circulation in the nontornadic supercell (not shown). The nontornadic supercells do not have a broad, consistent upward-directed vertical perturbation pressure gradient to stretch subtornadic surface vortices into a tornado and to mitigate the downward-directed dynamical accelerations associated with these developing vortices (see Fig. 17 in $\mathrm{C} 17 \mathrm{a}$; cf. Figs. 8 and 15 in $\mathrm{C} 17 \mathrm{~b}$ ). The lack of correlation between the low-level cyclonic circulation and the main updraft is a persistent feature of the nontornadic supercells throughout a \pm 5 -min time period centered on the time of tornadogenesis failure (Figs. S2a,b). This indicates that these nontornadic mesocyclones are configured suboptimally throughout the potential tornadogenesis period, not just right at the key time of tornadogenesis failure. This is true across a range of different horizontal and vertical grid spacing configurations (not shown), implying that the "disorganization" of the nontornadic mesocyclones is not due to differences in the resolved flow.
In contrast, as the low-level wind profiles are increasingly adjusted toward the tornadic wind profile, the low-level updraft progressively becomes more in sync with the low-level mesocyclone (Figs. 9c-f, S2c-f), as predicted by Davies-Jones (1984). Spatial correlations between the updraft and circulation fields increase from 0.175 to 0.783 , with higher ratios of streamwise to crosswise horizontal vorticity (Fig. 9). This high correlation in the four tornadic supercells, not only at the time of tornadogenesis but also preceding it, leads to the steady upward dynamic accelerations (through the nonlinear dynamic "spin" term) of the low-level mesocyclone overtop of the zone of available subtornadic vertical vorticity and thus, eventually, tornadogenesis (as discussed in more detail in $\mathrm{C} 17 \mathrm{a}, \mathrm{b}$ ).

Directly comparing the simulations on either side of the tipping point between nontornadic and tornadic supercells (i.e., $20 \%$ vs $40 \%$ tornadic low-level winds), both storms possess a strong updraft in the midlevels (i.e., 3-7 km AGL) throughout much of the simulation, with vertical velocities exceeding $40 \mathrm{~m} \mathrm{~s}^{-1}$ (Figs. 10a,b). Comparing the three-dimensional updraft structures prior to tornadogenesis is even more enlightening. The $20 \mathrm{~m} \mathrm{~s}^{-1}$ updraft isosurface in the tornadic 40torLLW supercell extends to a lower altitude and is centered 


\section{Nontornadic VORTEX2 interpolated simulations:}

$1 \mathrm{~km}$ vertical velocity

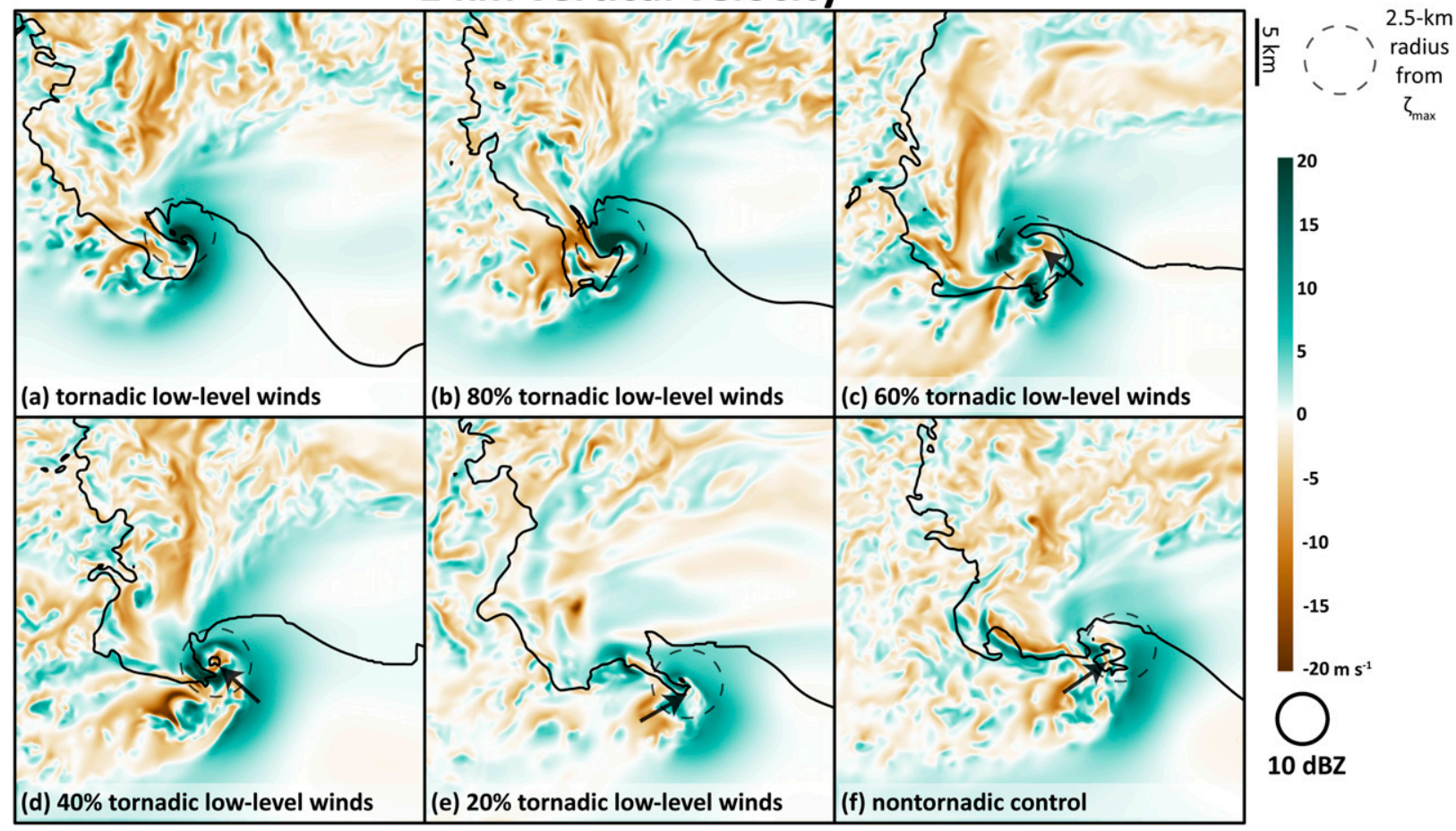

FIG. 13. As in Fig. 6, but for the nontornadic VORTEX2 interpolated simulations. Refer to Table 2 for the key time period for each simulation. The dashed circle in each panel encloses the $2.5-\mathrm{km}$-radius ring around the surface vertical vorticity maximum at the key time period.

upon the developing tornado (Fig. 11a). On the other hand, the updraft isosurface for the nontornadic 20torLLW supercell remains farther aloft and is significantly detached in the vertical from the near-surface rotation (i.e., the narrow black isosurfaces near the surface in Fig. 11b).

\section{b. Characteristics of the interpolated simulations based on the nontornadic VORTEX2 environment}

In the second suite of simulations, the initial conditions consist of the thermodynamic profile and upper-level winds from the nontornadic VORTEX2 composite, with varying low-level wind profiles (Table 2, Fig. 1). One simulation possesses the tornadic VORTEX2 low-level wind profile (i.e., ntV2-torLLW simulation; Table 2, Fig. 1). The next four simulations have a low-level wind profile linearly interpolated between the nontornadic and tornadic VORTEX2 composite environments at $20 \%$ intervals (e.g., ntV2-20torLLW simulation; Table 2, Fig. 1). The ntV2-control simulation is the same as in C17b.

There is a less-defined transition from tornadic to nontornadic supercells in this set of interpolated simulations. Both the ntV2-torLLW and the
ntV2-80torLLW simulations have distinct hook echoes at the key time period (Figs. 12a,b). With increasing environmental crosswise horizontal vorticity, the hook echoes become progressively disorganized (Figs. 12c-f). Likewise, the disorganization is evident in the lowlevel updraft (Fig. 13). The ntV2-torLLW and the ntV2-80torLLW simulations generally have a robust updraft at $1 \mathrm{~km}$ overlying the intensifying near-surface circulation (Figs. 13a,b). At the key time period, the ntV2-80torLLW simulation has a weak, transient area of descent within and adjacent to the rear-flank precipitation (Fig. 13b); however, the developing nearsurface rotation is underneath the intense low-level updraft, with vertical velocities exceeding $40 \mathrm{~m} \mathrm{~s}^{-1}$. As more of the nontornadic wind profile is introduced, large areas of descent are increasingly present where the surface vertical vorticity resides (Figs. 13c-f). In addition to the structure of velocity field, the magnitude of the $1-\mathrm{km}$ updraft is reduced in the ntV2-20torLLW and the ntV2-control simulations, and the distribution of the vertical velocity pixels mirrors that of the tornadic VORTEX2 interpolated simulations shown in Fig. 8 (not shown). 
Nontornadic VORTEX2 interpolated simulations: Translated maximum surface vertical vorticity

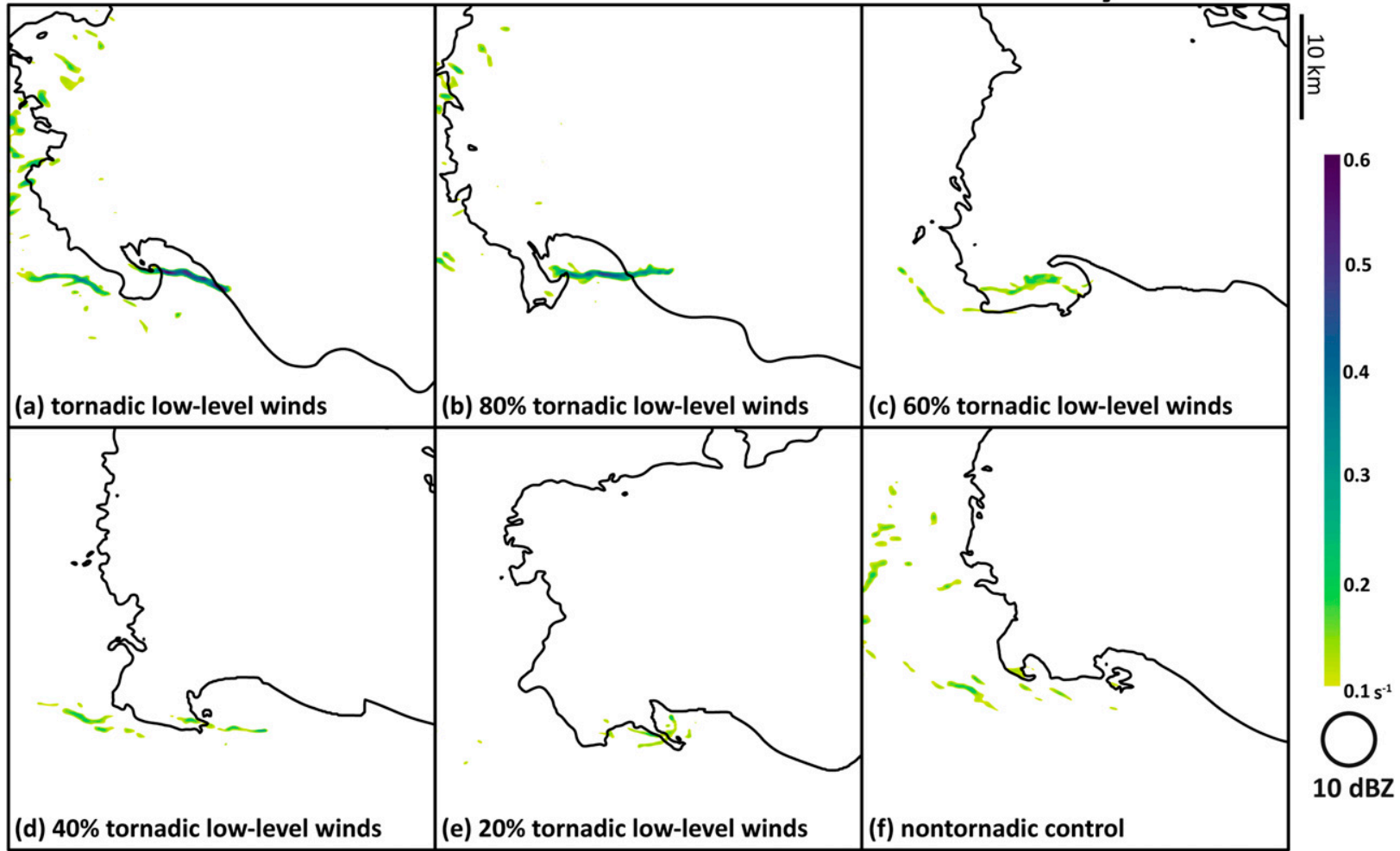

FIG. 14. As in Fig. 3, but for the nontornadic VORTEX2 interpolated simulations. Refer to Table 2 for the key time period for each simulation.

These updraft differences lead to fairly expected trends in tornado production. Both the ntV2-torLLW and the ntV2-80torLLW produce tornadic supercells (Figs. 14a,b), with the former being more intense than the latter. Even so, neither of the tornadic vortices herein is as impressive as those in the interpolated simulations based on the tornadic VORTEX2 environment (Figs. 3c-f). Perhaps this is simply due to pure chance. An alternate hypothesis is that differences in the thermodynamic profile between the VORTEX2 composite environments lead to a higher probability of intense tornadoes (this hypothesis is explored further in section $3 \mathrm{~d})$.

In contrast, the ntV2-60torLLW simulation is weakly tornadic (Fig. 14c), while the following three simulations fail to produce a tornado (Figs. 14d-f). These failures occur in spite of ample subtornadic surface vertical vorticity available for stretching in each of the simulations (Fig. S3). Interestingly, the 0-500-m SRH in the weakly tornadic ntV2-60torLLW simulation $\left(114 \mathrm{~m}^{2} \mathrm{~s}^{-2}\right.$; Table 2) falls between the nontornadic and tornadic SRH thresholds from the tornadic
VORTEX2 interpolated simulations $\left(105-118 \mathrm{~m}^{2} \mathrm{~s}^{-2}\right.$; Table 2). ${ }^{5}$

It is not obvious from the near-surface buoyancy alone which of these storms would be tornadic (Fig. 15). It is well established that nontornadic supercells typically have colder near-surface outflow temperatures that inhibit the stretching required for tornadogenesis (e.g., Markowski et al. 2002). As in the tornadic VORTEX2 interpolated simulations, all six storms have relatively weak cold pools. Despite producing the most intense tornado, the ntV2-torLLW simulation has the coldest hook echo outflow temperatures (Fig. 15a), which

\footnotetext{
${ }^{5}$ Differences in the upper-level winds (i.e., slightly more backed winds aloft in the nontornadic VORTEX2 environment) lead to a calculated storm motion (Bunkers et al. 2000) falling closer to the hodograph. Similar to the simulations by Parker (2017), this "backing aloft" (sometimes referred to as a "veer back veer" wind profile) marginally reduces the amount of SRH in the nontornadic VORTEX2 interpolated suite of simulations, compared to the tornadic suite for the same low-level wind profile (e.g., torV2-20torLLW vs ntV2-20torLLW in Table 2).
} 


\section{Nontornadic VORTEX2 interpolated simulations: Density potential temperature perturbation}

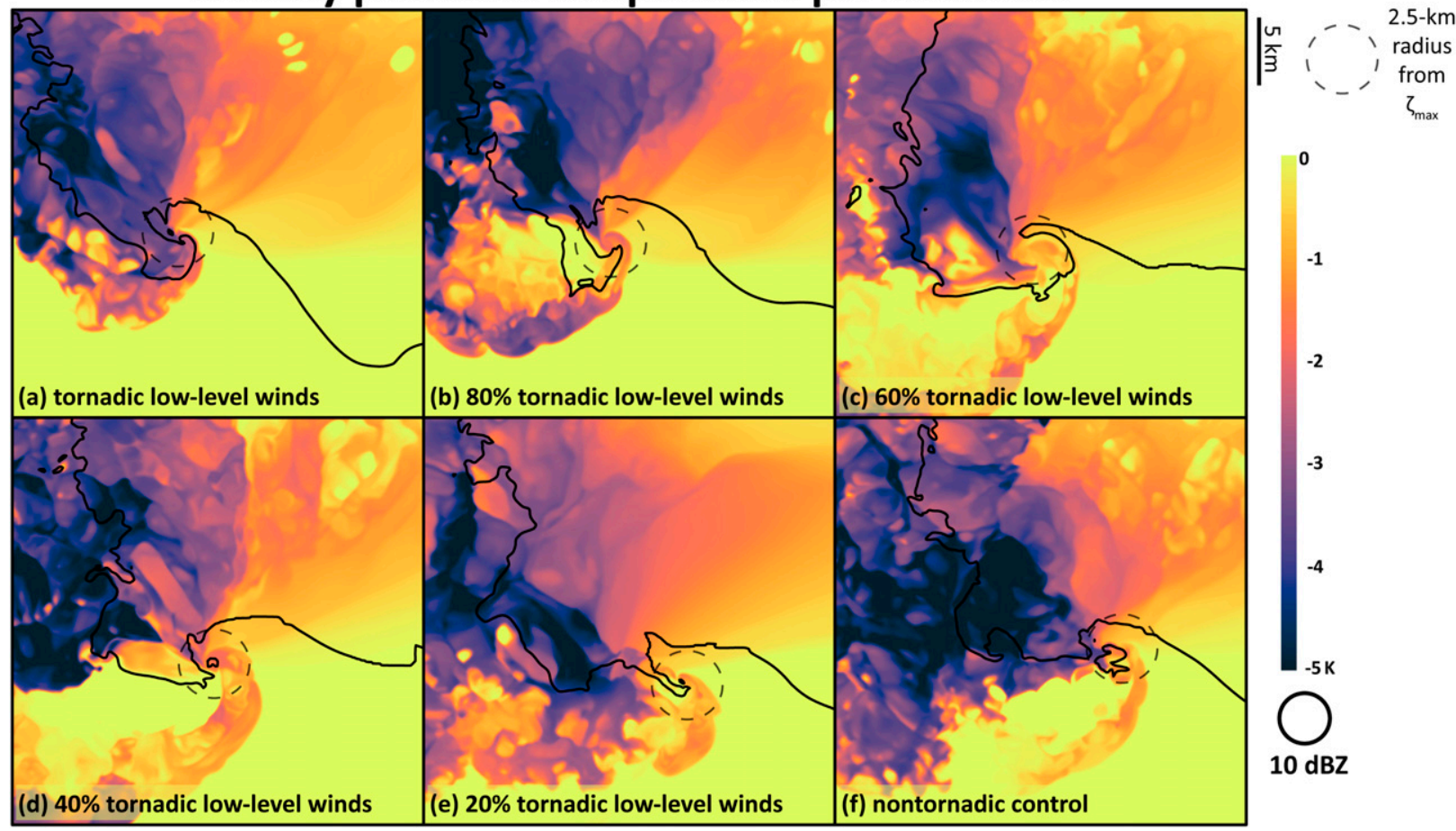

FIG. 15. As in Fig. 4, but for the nontornadic VORTEX2 interpolated simulations. Refer to Table 2 for the key time period for each simulation. The dashed circle in each panel encloses the $2.5-\mathrm{km}$-radius ring around the surface vertical vorticity maximum at the key time period used in Fig. 16.

exceeds what is typically found in significantly tornadic supercells (>-3; Markowski et al. 2002; Grzych et al. 2007). During a 10-min window centered on the key time period, the three nontornadic supercells actually have relatively warm density potential temperature deficits within a $2.5-\mathrm{km}$ radius of the vertical vorticity maximum, while the weakly tornadic supercell's outflow is near average (Fig. 16). This implies that excessively negatively buoyant air in the vicinity of the near-surface rotation is not the failure mode of tornadogenesis in the interpolated simulation suite based on the nontornadic VORTEX2 environment (a universal theme of all the VORTEX2 composite simulations presented herein and in $\mathrm{C} 17 \mathrm{a}, \mathrm{b})$.

As crosswise horizontal vorticity is increased in the lower troposphere, the low-level updraft and cyclonic circulation maximum become increasingly disconnected with each other (Fig. 17). The intensity of the low-level updraft noticeably declines as well. The low-level cyclonic circulation couplet is primarily in phase with the upward vertical velocity in the tornadic supercells and is associated with a closed circulation, rather than a deformational wind field (Figs. 17a,b). Spatial correlations between the updraft and the circulation fields are near 0.7 for the two tornadic supercells. In contrast, as the low-level wind profile is increasingly shifted toward the nontornadic wind profile, the low-level updraft

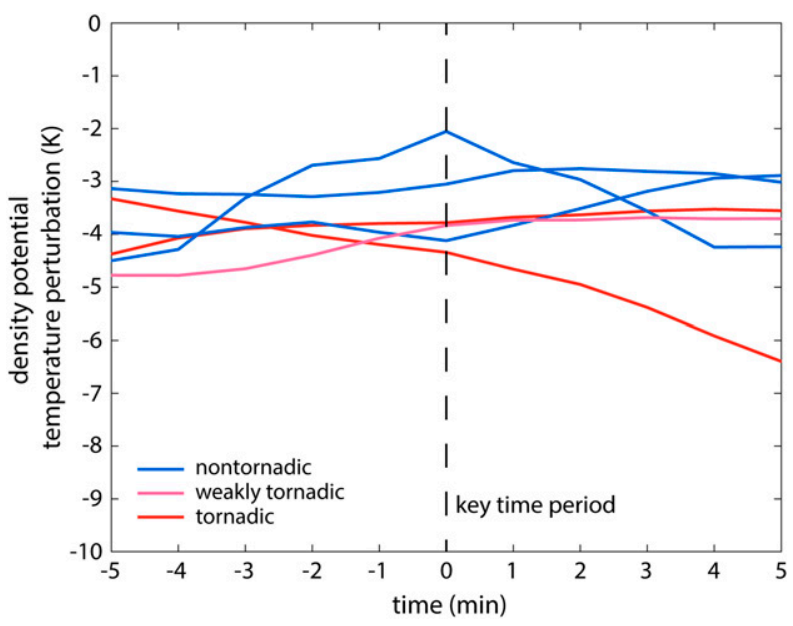

FIG. 16. As in Fig. 5, but for the nontornadic VORTEX2 interpolated simulations. Refer to Table 2 for a list of which simulations are tornadic or not. 


\section{Nontornadic VORTEX2 interpolated simulations:}

\section{$1 \mathrm{~km}$ circulation}

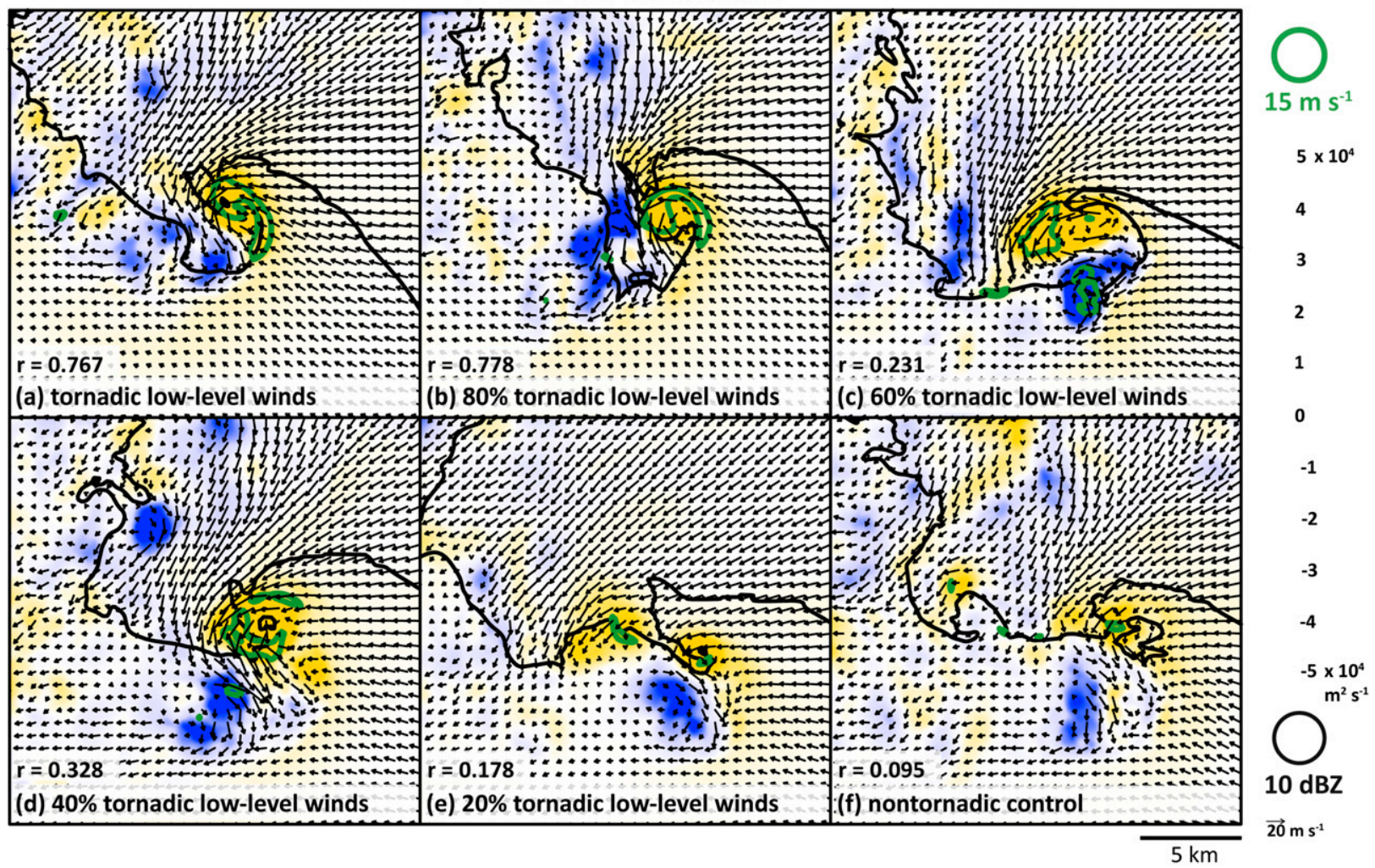

FIG. 17. As in Fig. 9, but for the nontornadic VORTEX2 interpolated simulations. Refer to Table 2 for the key time period for each simulation.

steadily becomes less synchronized with the low-level mesocyclone (Figs. 17c-f), with updraft and circulation correlations ranging from 0.095 to 0.328 in the nontornadic supercells. The lack of correlation between the updraft and the cyclonic circulations leads the unsteady nature of the dynamic lifting of the mesocyclone and areas of minimal upward dynamic accelerations (or even downward accelerations), a configuration not favorable for tornadogenesis (as discussed in more detail in $\mathrm{C} 17 \mathrm{a}, \mathrm{b}$, as well as section 3 b herein).

In the previous section, a head-to-head comparison was made between the pair of simulations that represented a tipping point from nontornadic to tornadic storms. In this case, the differences between the weakly tornadic ntV2-60torLLW simulation and the nontornadic ntV2-40torLLW are minimal. One potentially important ramification of this work is that weakly tornadic supercell simulations share many analogous characteristics with nontornadic supercell simulations. In nature, weakly tornadic storms likely have many similarities with nontornadic storms, but serendipitously produce weak, brief tornadoes due to finescale (essentially stochastic) differences. Therefore, for the suite of interpolated runs based on the nontornadic VORTEX2 environment, a comparison is shown for the tornadic ntV2-80torLLW simulation and the nontornadic ntV2-20torLLW simulation in order to more clearly elucidate differences between nontornadic and tornadic supercells in the interpolated simulations based on the nontornadic VORTEX2 environment.

The main difference is once again that the low-level updraft is stronger in the tornadic ntV2-80torLLW simulation (Fig. 18a), with more near-surface streamwise horizontal vorticity versus the weaker low-level updraft in the nontornadic ntV2-20torLLW simulation (Fig. 18b). These differences in the low-level updraft velocity likely eventually alter the intensification of surface vortices (e.g., through stretching; Figs. 18c,d). Additionally, these differences are even more evident when shown three-dimensionally (Figs. 11c,d). 


\section{Nontornadic VORTEX2 interpolated simulations:}
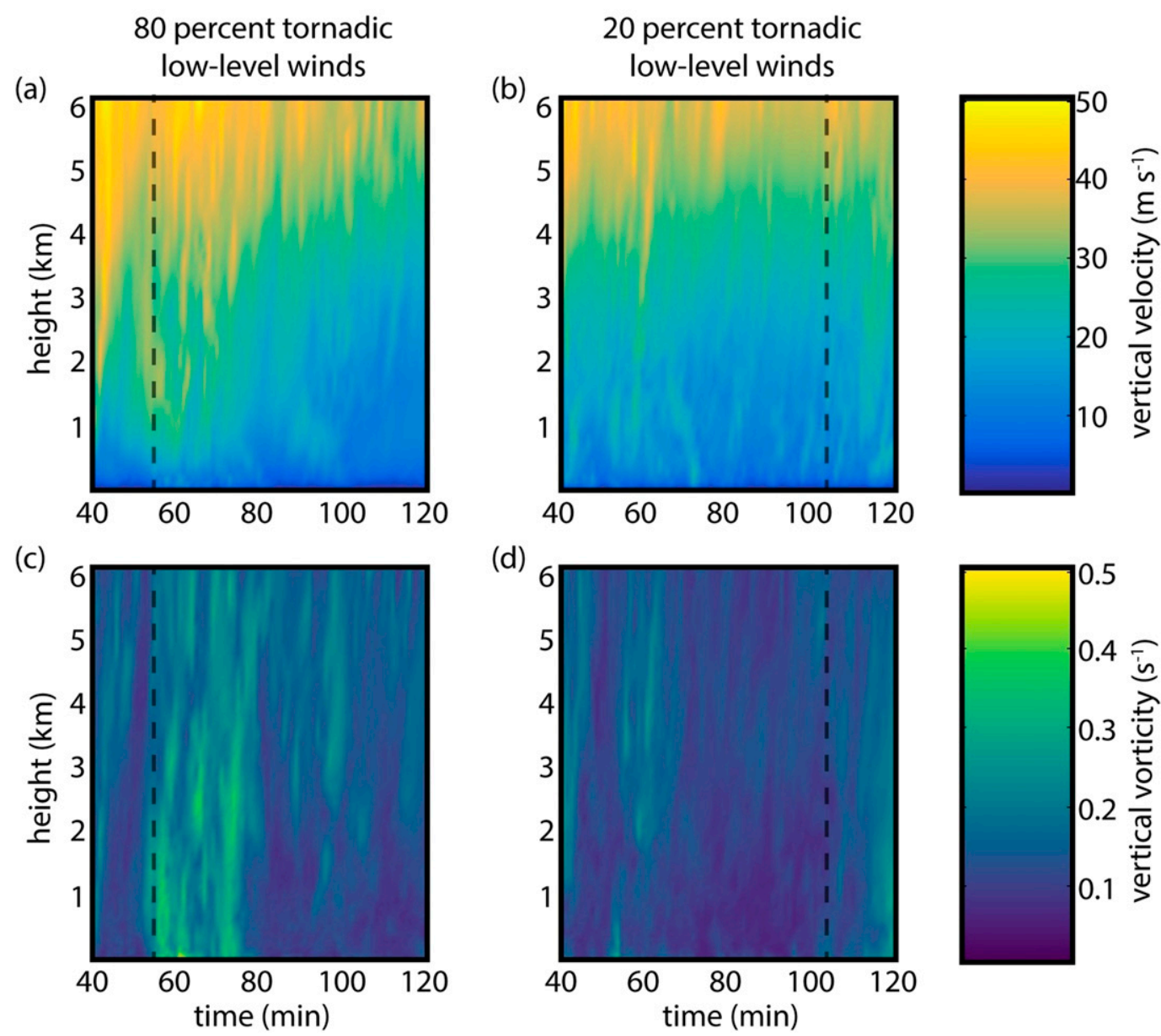

(d)
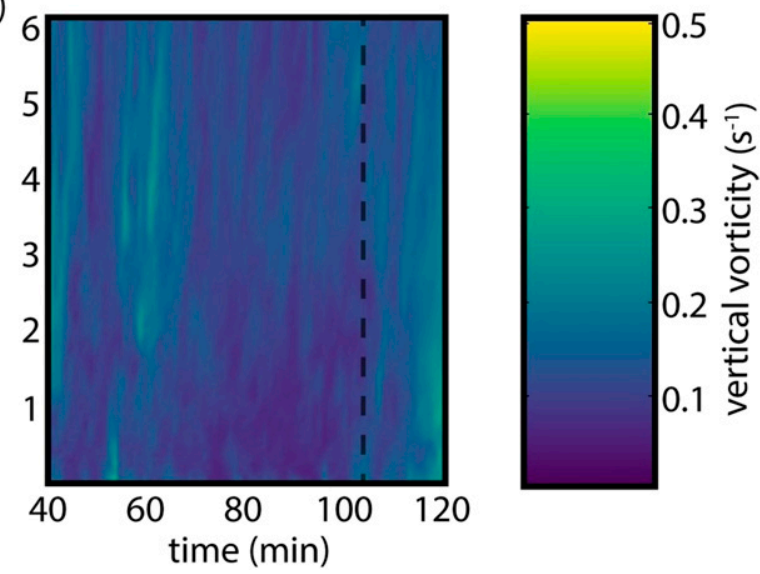

FIG. 18. Time-height plot of maximum (top) vertical velocity $\left(\mathrm{m} \mathrm{s}^{-1}\right)$ and (bottom) vertical vorticity $\left(\mathrm{s}^{-1}\right)$ in a $50-\mathrm{km}^{2}$ box following the midlevel mesocyclone for the (left) $80 \%$ and (right) $20 \%$ tornadic LLW simulations from the nontornadic VORTEX2 interpolated suite of simulations. The dashed black line indicates the key time period of tornadogenesis or tornadogenesis failure for each simulation (Table 2).

The tornadic supercell has a robust updraft at low levels superimposed with the deep tornadic vortex (Figs. 11c,d), while the nontornadic supercell has a much weaker low-level updraft at the key time period and lacks a meaningful surface vortex (Figs. 11c,d).

\section{c. Mini-ensembles of the VORTEX2 interpolated simulations}

In C17b, an ensemble of supercells was simulated to understand the volatility of tornado production for storms in similar environments. Therefore, it is natural to ask how representative the results are from the interpolated simulations in sections $3 \mathrm{a}$ and $3 \mathrm{~b}$. To this end, four additional ensemble members were simulated for both the nontornadic low-level winds (torV2-ntLLW;
Figs. $2 a-4 a$ and $6 a-9 a)$ and the tornadic low-level winds simulations (ntV2-torLLW; Figs. 12a-15a and 17a). These are not the control members from $\mathrm{C} 17 \mathrm{a}, \mathrm{b}$, but rather the simulations that contain the full thermodynamic profile and upper-tropospheric winds from one VORTEX2 composite environment with the opposite composite environment's lower-tropospheric wind profile. The ensemble was initialized using the same method as described in $\mathrm{C} 17 \mathrm{~b}$, albeit with fewer ensemble members. Horizontal wind perturbations generated from a uniform distribution with a maximum magnitude of $2 \mathrm{~m} \mathrm{~s}^{-1}$ were added to the wind profiles, irrespective of height. The mean of the perturbations applied to each wind profile is practically zero, and the perturbations are identical between the nontornadic low-level winds and the tornadic low-level winds 
TABLE 3. Summary of the five-member ensemble for both the nontornadic and tornadic LLW interpolated simulations. The tornadogenesis criteria are outlined in $\mathrm{C} 17 \mathrm{~b}$. In short, the key time period is either the time of tornadogenesis or the time of maximum surface vertical vorticity, if a supercell did not meet the criteria.

\begin{tabular}{lll}
\hline \hline & \multicolumn{1}{c}{ Tornadic? } & Key time period (min) \\
\hline $\begin{array}{l}\text { Tornadic VORTEX2 interpolated simulations: Nontornadic } \\
\text { low-level winds }\end{array}$ & & \\
Control & Nontornadic & $t=70$ \\
Member01 & Nontornadic & $t=53$ \\
Member02 & Nontornadic & $t=61$ \\
Member03 & Nontornadic & $t=54$ \\
Member04 & Nontornadic & $t=47$ \\
Nontornadic VORTEX2 interpolated simulations: Tornadic \\
low-level winds & & \\
Control & Tornadic & $t=58$ \\
Member01 & Weakly tornadic & $t=52$ \\
Member02 & Tornadic & $t=57$ \\
Member03 & Tornadic & $t=51$ \\
Member04 & Nontornadic & $t=70$ \\
\hline
\end{tabular}

simulations. It was not computationally feasible to reproduce an entire 15 -member ensemble for all the interpolated simulations; therefore, a five-member mini-ensemble of just the base low-level wind profiles was performed instead (i.e., torV2-ntLLW and ntV2-torLLW).

For the torV2-ntLLW mini-ensemble, all five members failed to produce a tornadic supercell (Table 3). In contrast, for the ntV2-torLLW mini-ensemble, three of the members were tornadic, one produced a weakly tornadic supercell, and one failed to produce a tornado (Table 3). These additional ensemble members indicate that the results from the deterministic sensitivity tests are largely robust. Near-surface streamwise horizontal vorticity generally favors tornadic supercells across a wide range of varied environments. However, the range of tornadogenesis outcomes is more volatile when the tornadic low-level winds are combined with the nontornadic thermodynamic profile and upper-level winds (i.e., compared to the tornadic VORTEX2 ensemble from $\mathrm{C} 17 \mathrm{~b}$ ).

Although we know that not every storm is tornadic (even in environments known to be highly supportive of tornadogenesis), this volatility is an interesting result in light of the results presented in $\mathrm{C} 17 \mathrm{~b}$ (i.e., all of the tornadic VORTEX2 ensemble members produced tornadoes). One speculative conclusion from the miniensemble herein is that the upper-level winds or the thermodynamic profile (or some combination of both) of the nontornadic VORTEX2 composite leads to a lower intrinsic probability of tornadogenesis (despite the highly streamwise horizontal vorticity of the tornadic low-level wind profile), perhaps due to the backing of winds at $3-5 \mathrm{~km}$ AGL or the less-favorable buoyancy/ humidity profiles throughout the troposphere. The tornadic VORTEX2 composite might fortuitously have an optimal combination of parameters that make it so robustly favorable for tornadogenesis. However, it is difficult to isolate the roles of individual environmental ingredients directly upon tornadogenesis in full-physics simulations. Nonetheless, in the next section, the influence of differences in the VORTEX2 composite thermodynamic profiles on tornado production is considered further.

\section{d. Thermodynamic sensitivity tests in the VORTEX2 composite environments}

Previous research has indicated that certain thermodynamic variables lead to a higher probability of tornadogenesis. For example, higher CAPE and less CIN are known to favor significantly tornadic supercells versus nontornadic supercells (e.g., Thompson et al. 2003). Additionally, tornadogenesis is more likely when cold pools are not excessively negatively buoyant (e.g., Markowski 2002; Markowski and Richardson 2014; Grzych et al. 2007). This occurs when there is higher low-level relative humidity and lower LCLs (i.e., less potential for evaporative cooling). Finally, it has been suggested that updraft strength and vertical vorticity are enhanced when buoyancy is concentrated in the lower troposphere of environmental profiles (e.g., McCaul and Weisman 2001; Rasmussen 2003; Davies 2006; Hampshire et al. 2018). Overall, the tornadic VORTEX2 composite environment is somewhat more favorable for tornadoes by these conventional thermodynamic measures, including slightly more surface-based CAPE (2755 vs $2377 \mathrm{~J} \mathrm{~kg}^{-1}$ ) and 0-3-km AGL CAPE ( 86 vs $40 \mathrm{~J} \mathrm{~kg}^{-1}$ ), less surface-based CIN ( -39 vs $-43 \mathrm{~J} \mathrm{~kg}^{-1}$ ), lower surface-based LCLs ( 845 vs $1129 \mathrm{~m})$, and higher low-level $(74 \%$ vs $65 \%)$ and midlevel $(60 \%$ vs $56 \%)$ relative humidity. ${ }^{6}$ The philosophy from the beginning of this research has been that these thermodynamic differences between the nontornadic and tornadic VORTEX2 composite environments are not particularly striking, and the most important difference was in the lower-tropospheric wind profile, specifically the orientation of the horizontal vorticity in the lowest $500 \mathrm{~m}$ AGL. This reasoning is supported by the dry idealized updraft simulations in $\mathrm{C} 17 \mathrm{a}$, which were used to show that the strength and steadiness of the low-level mesocyclone, and the associated dynamic lifting, could be directly

\footnotetext{
${ }^{6}$ All parameters were calculated using the Sounding/Hodograph Analysis and Research Program in Python (SHARPpy) software (Blumberg et al. 2017).
} 


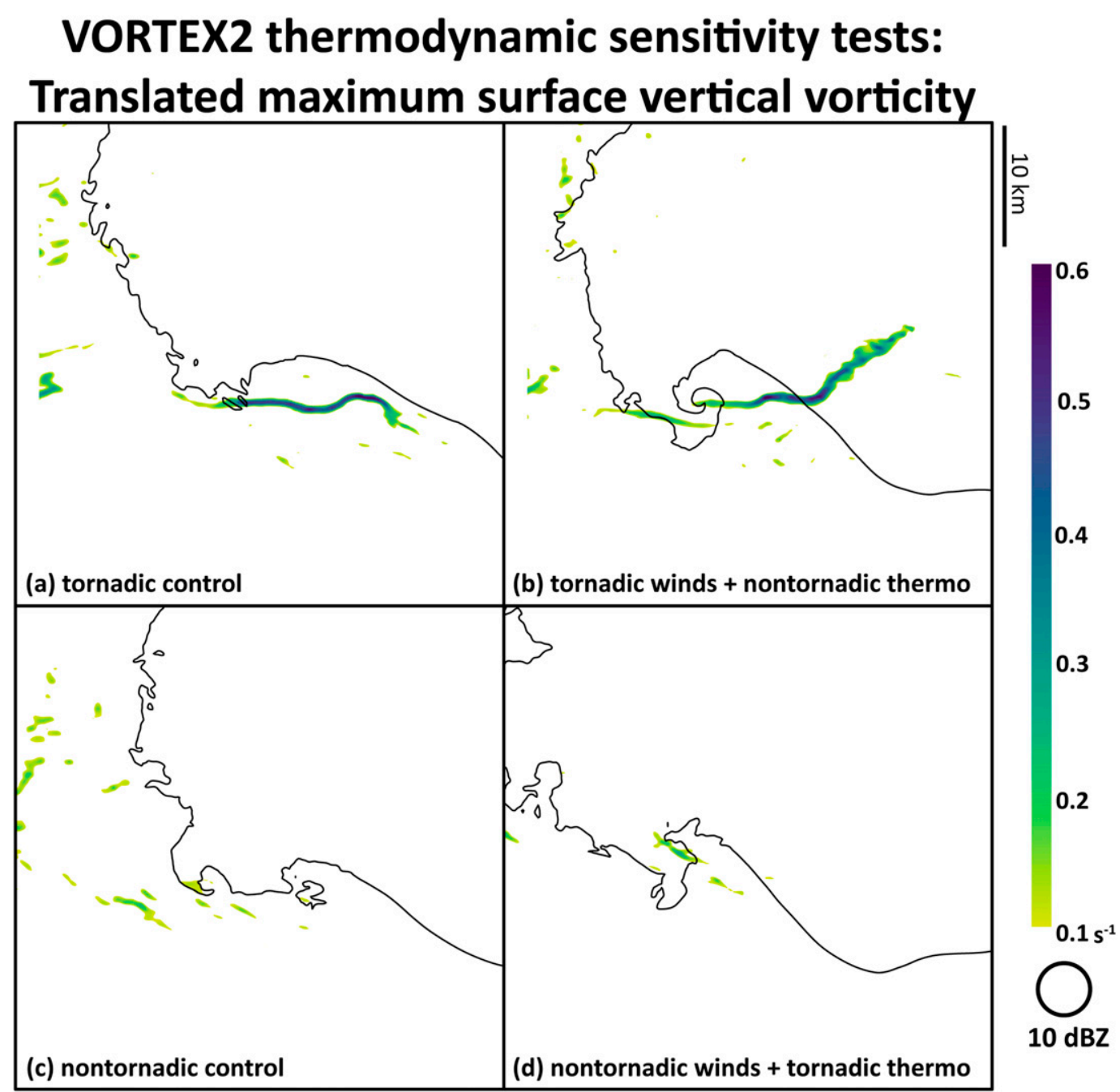

FIG. 19. Horizontal cross sections of $10 \mathrm{~m}$ AGL translated maximum vertical vorticity $\left(\mathrm{s}^{-1}\right.$; shaded) at the key time period of tornadogenesis or tornadogenesis failure for the VORTEX2 thermodynamic sensitivity tests. The $10-\mathrm{dB} Z$ reflectivity contour (black) at $10 \mathrm{~m}$ AGL for the respective simulations is shown for reference. The key time periods are $t=$ (a) 54, (b) 55, (c) 79, and (d) $73 \mathrm{~min}$.

attributed to the differences in the lower-tropospheric streamwise versus crosswise vorticity.

Even so, in order to further test whether differences in the thermodynamic profile ultimately contribute to tornadogenesis or tornadogenesis failure in the VORTEX2 composite environments using a full-physics model configuration, simulations were performed swapping the thermodynamic profile between the nontornadic and tornadic composites (i.e., storms were simulated using the tornadic wind profile with the nontornadic thermodynamic profile, and vice versa). In Figs. 19-23, these swapped thermodynamic simulations are compared to the control members of the VORTEX2 ensembles from $\mathrm{C} 17 \mathrm{~b}$ and sections $3 \mathrm{a}$ and $3 \mathrm{~b}$ herein.
Regardless of the thermodynamic profile, the two simulations with the tornadic wind profile produce a tornadic supercell (Figs. 19a,b), while both of the simulations with the nontornadic winds do not (Figs. 19c,d). As in previous simulations, the presence of hook echoes (Fig. S4), only moderately negatively buoyant air (Fig. 20), and plenty of subtornadic vertical vorticity (Fig. S5) are not determinative of a storm's tornadic potential. Instead, the differences in the low-level updraft are the main drivers of whether a storm undergoes tornadogenesis or not. Both simulations with the nontornadic wind profile have relatively weak low-level updrafts throughout the simulation (Figs. S6a,c) and produce minimal vertical vorticity (Figs. S6b,d). In the two simulations 


\section{VORTEX2 thermodynamic sensitivity tests: Density potential temperature perturbation}

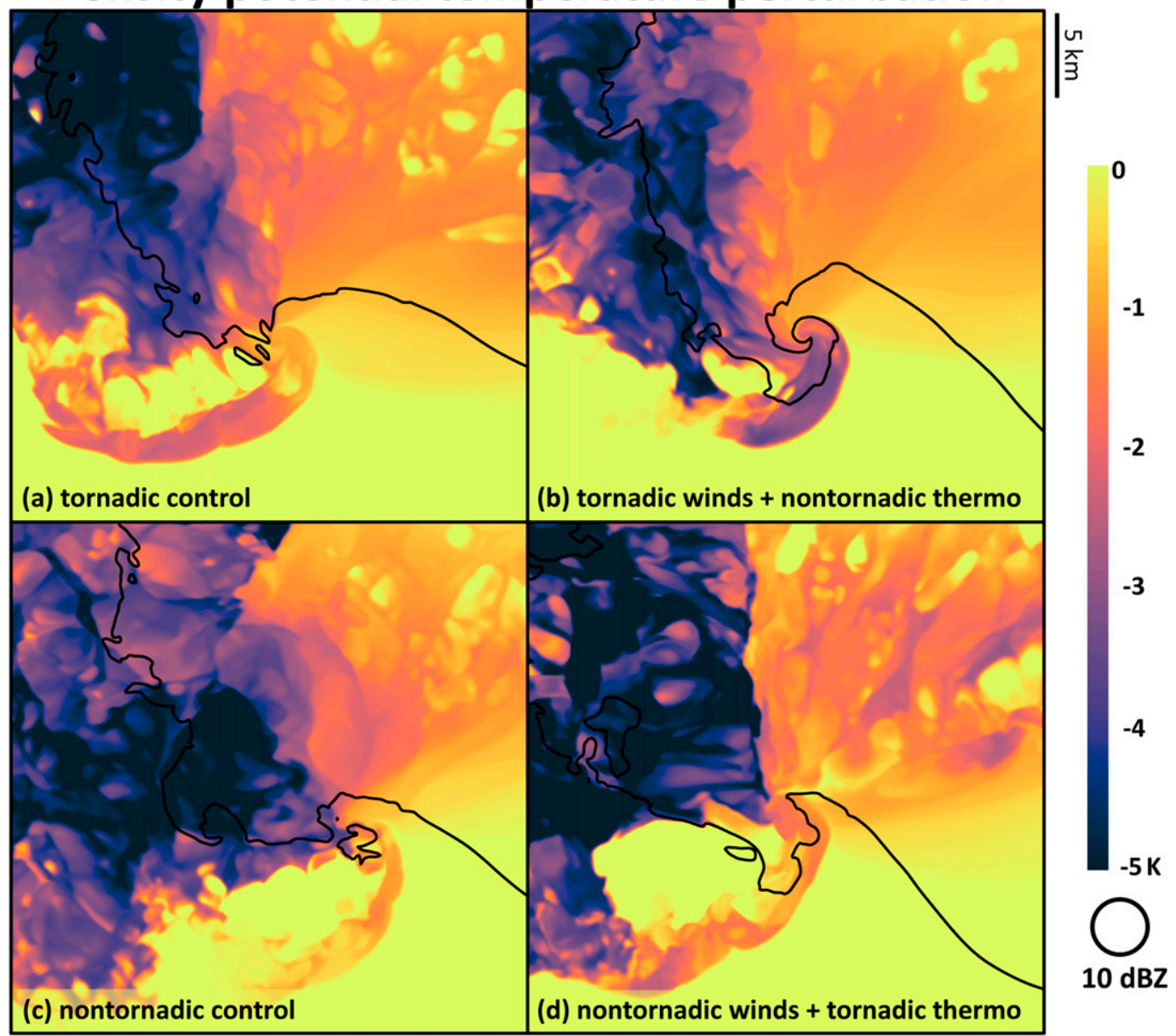

FIG. 20. As in Fig. 19, but for horizontal cross sections of $10 \mathrm{~m}$ AGL density potential temperature perturbation (K; shaded).

with the tornadic wind profile, the updraft in the lowest kilometer is particularly strong (Figs. S7a,c), which aids in the development of substantial vertical vorticity throughout the depth of the storm (Figs. S7b,d).

Spatially, this is manifested as a broad area of strong upward motion at $1 \mathrm{~km}$ AGL directly overtop of the intensifying near-surface circulation in the simulations with the tornadic winds (Figs. 21a,b). This is a consistent, fundamental feature in every simulation herein with the tornadic low-level wind profile. In the nontornadic wind simulations, the updraft is notably unsteady, with pockets of descent present where the surface vertical vorticity resides (within and adjacent to the rear-flank precipitation; Figs. 21c,d), consistent with the baseline nontornadic simulation of $\mathrm{C} 17 \mathrm{a}$ and the nontornadic VORTEX2 ensemble in C17b. Parcels that acquired vertical vorticity near the surface in the nontornadic supercell fail to be lifted and stretched into the overlying storm.

To further assess whether the wind profile is the dominant contributor to storm-scale differences between the simulations, the buoyant and dynamic components of acceleration are compared. If the differences in CAPE and CIN between the two environments are actually important to the storm's potential for tornado production, then one would expect to see notable differences in either the cold pool strength or the buoyant forcing. However, the surface cold pools are not excessively cold (Fig. 20), and the total buoyant acceleration $\left[-(1 / \rho)\left(\partial p_{b}^{\prime} / \partial z\right)+B\right]$ at $1 \mathrm{~km}$ AGL is relatively uniform across each of the VORTEX2 thermodynamic sensitivity tests (Fig. 22). In general, an expansive area of 


\section{VORTEX2 thermodynamic sensitivity tests: $1 \mathrm{~km}$ vertical velocity}

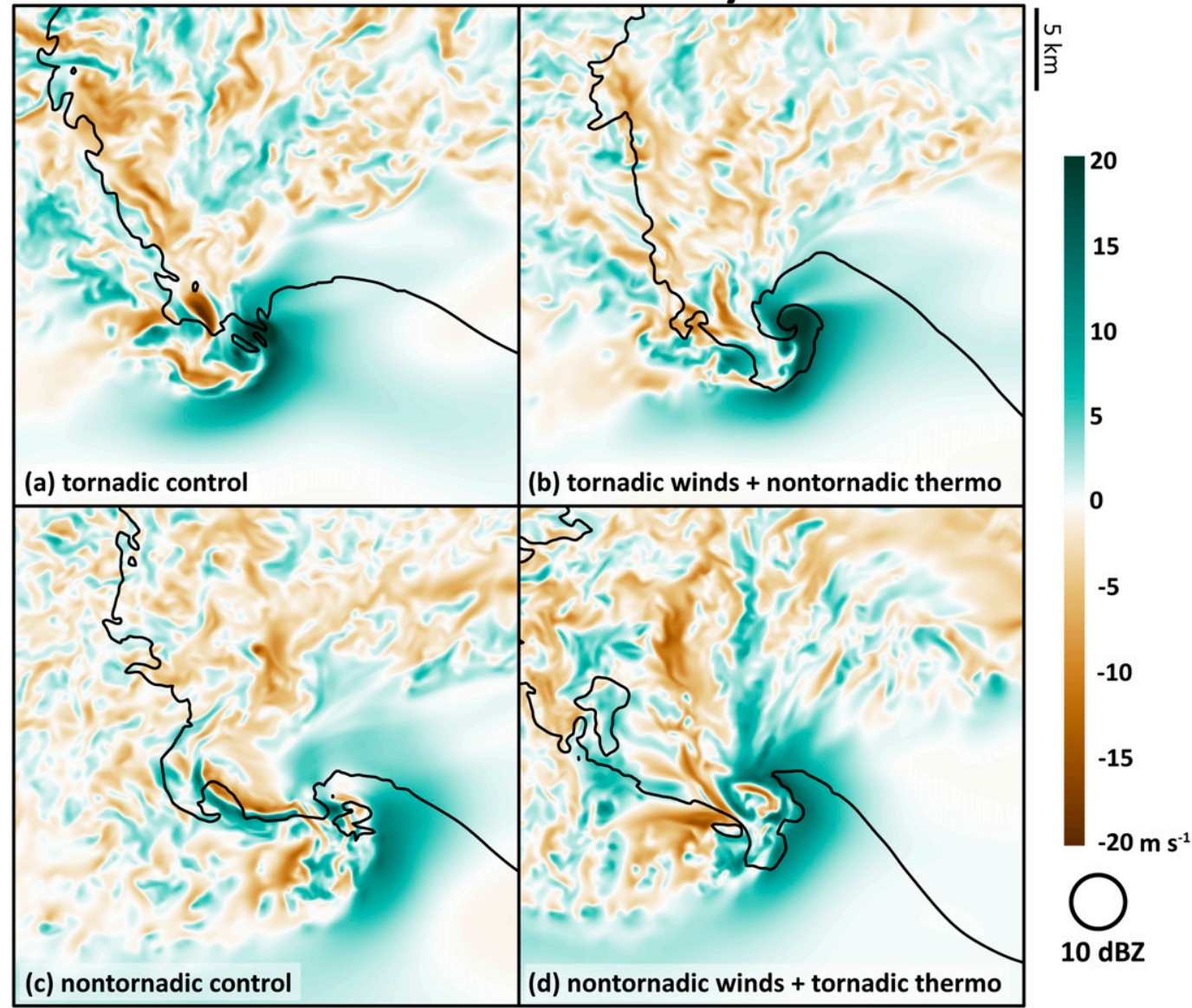

FIG. 21. As in Fig. 19, but for horizontal cross sections of $1 \mathrm{~km} \mathrm{AGL} \mathrm{vertical} \mathrm{velocity} \mathrm{(} \mathrm{m} \mathrm{s}^{-1}$; shaded).

positive buoyant acceleration encompasses much of the weak echo region (Fig. 22). On the other hand, the dynamic acceleration at $1 \mathrm{~km}$ AGL is greater in magnitude than the buoyant forcing (Fig. 23). In the nontornadic wind profile simulations, however, the dynamic acceleration field is strikingly disorganized (Figs. 23c,d), as both positive and negative areas of acceleration are dispersed throughout the hook echo region. Without a persistent area of upward lifting, the surface vorticity that does develop in the nontornadic supercell is not likely to be contracted into a tornado. In contrast, in the tornadic wind profile simulations, there is a sustained area of upward dynamic accelerations directly above the rear-flank precipitation (Figs. 23a,b), where both of the tornadoes will eventually form (Figs. 19a,b). In summary, despite the variations in the values of CAPE and CIN (among other differences in the thermodynamic profile) between the nontornadic and tornadic VORTEX2 composite environments, the differences do not account for substantial changes in the buoyant acceleration field or the outflow properties. Instead, the low-level wind profile drives distinct configurations of the low-level mesocyclone, evident in the dynamic acceleration differences.

Comparing the vertical velocity field to the buoyant and dynamic accelerations reveals that in the nontornadic wind profile simulations, the main low-level updraft, which is bowed out along the rear-flank outflow and ahead of the hook echo, is primarily driven via buoyancy (cf. Figs. 21a,b with Figs. 22a,b). Conversely, the intense low-level updraft in the tornadic wind profile simulations, which is directly above the intensifying near-surface circulation, is strongly forced by large dynamic vertical accelerations (cf. Figs. 21a,b with Figs. 23a,b). As outlined previously in $\mathrm{C} 17 \mathrm{a}, \mathrm{b}$, the highly streamwise 
VORTEX2 thermodynamic sensitivity tests: $1 \mathrm{~km}$ buoyant acceleration

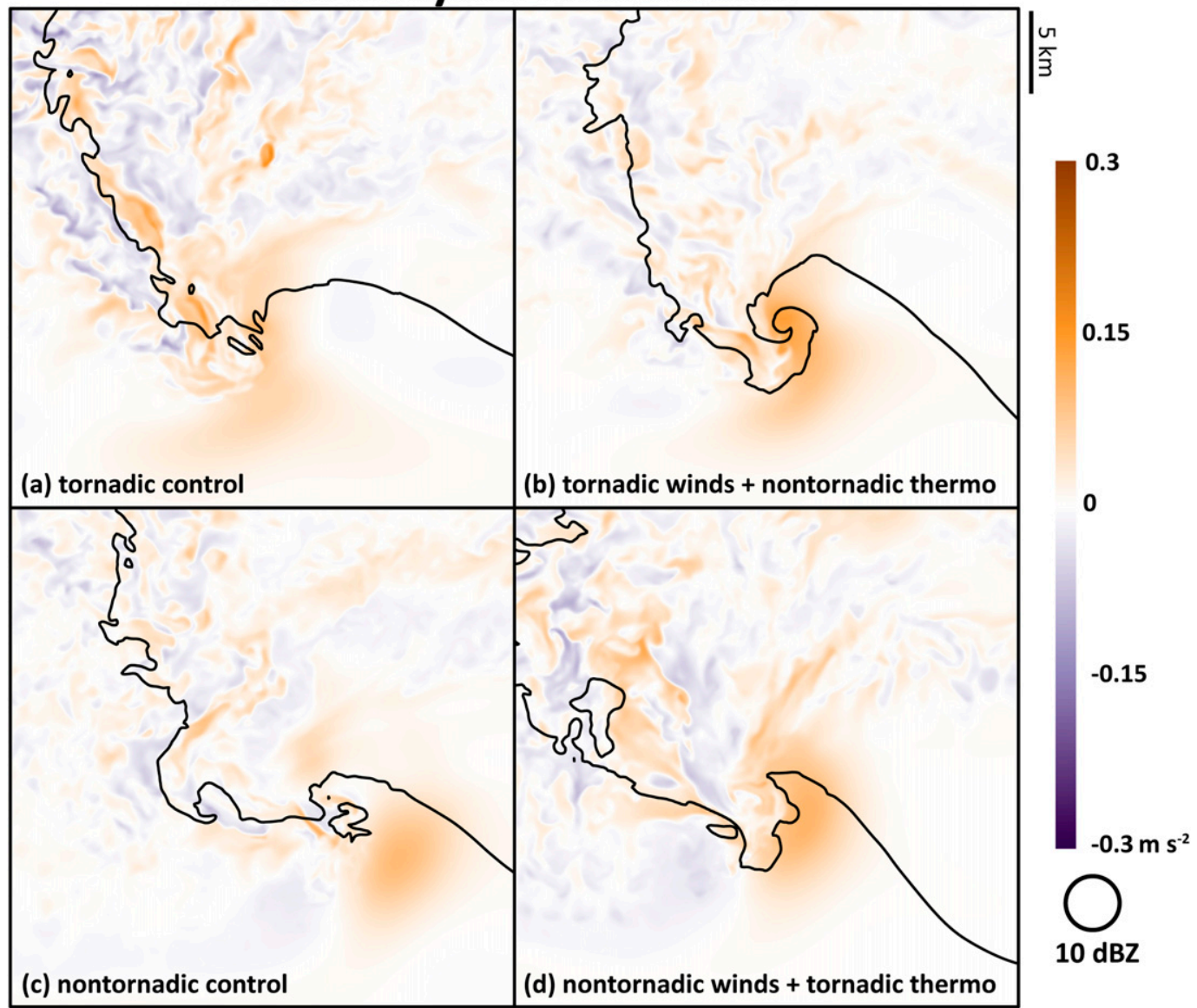

FIG. 22. As in Fig. 19, but for horizontal cross sections of $1 \mathrm{~km} \mathrm{AGL} \mathrm{total} \mathrm{buoyant} \mathrm{acceleration}\left[-(1 / \rho)\left(\partial p_{b}^{\prime} / \partial z\right)+B\right.$; $\mathrm{m} \mathrm{s}^{-2}$; shaded].

lower-tropospheric horizontal vorticity in the tornadic low-level wind profile consistently yields a storm configuration favorable for vigorous upward dynamic accelerations and, thus, tornadogenesis. These bulk differences in low-level updraft strength, vertical vorticity, and accelerations imply that the processes at work in the control simulations (discussed in depth in $\mathrm{C} 17 \mathrm{a}, \mathrm{b}$ ) are similar regardless of the thermodynamic profile.

\section{Summary and discussion}

From the simulations discussed in $\mathrm{C} 17 \mathrm{a}, \mathrm{b}$, it was unclear whether systematically varying the lowertropospheric horizontal vorticity would yield in a tipping point between nontornadic and tornadic supercells within the VORTEX2 composite environments. In other words, the prior experiments might pose this question: What amount of near-surface crosswise horizontal vorticity is necessary to disrupt the low-level mesocyclone sufficiently to prevent tornadogenesis?

The interpolated VORTEX2 simulations show that increasing lower-tropospheric SRH, and, consequently, decreasing the magnitude of crosswise horizontal vorticity, leads to progressively more organized low-level mesocyclones and a higher probability of tornadic supercells, regardless of the upper-level winds or thermodynamic profile of the two VORTEX2 environments tested herein. In these experiments, simulated supercells become tornadic when the low-level wind profile incorporates at least $40 \%$ of the structure of the tornadic VORTEX2 composite. The mean $0-500-\mathrm{m}$ SRH value where supercells are consistently tornadic for all the VORTEX2 interpolated simulations is $110 \mathrm{~m}^{2} \mathrm{~s}^{-2}$, although this exact value of $0-500-\mathrm{m}$ SRH is unlikely to universally discriminate between nontornadic and tornadic supercells in nature. Simulations that span a much broader range of the supercell spectrum, as 


\section{VORTEX2 thermodynamic sensitivity tests: $1 \mathrm{~km}$ dynamic acceleration}

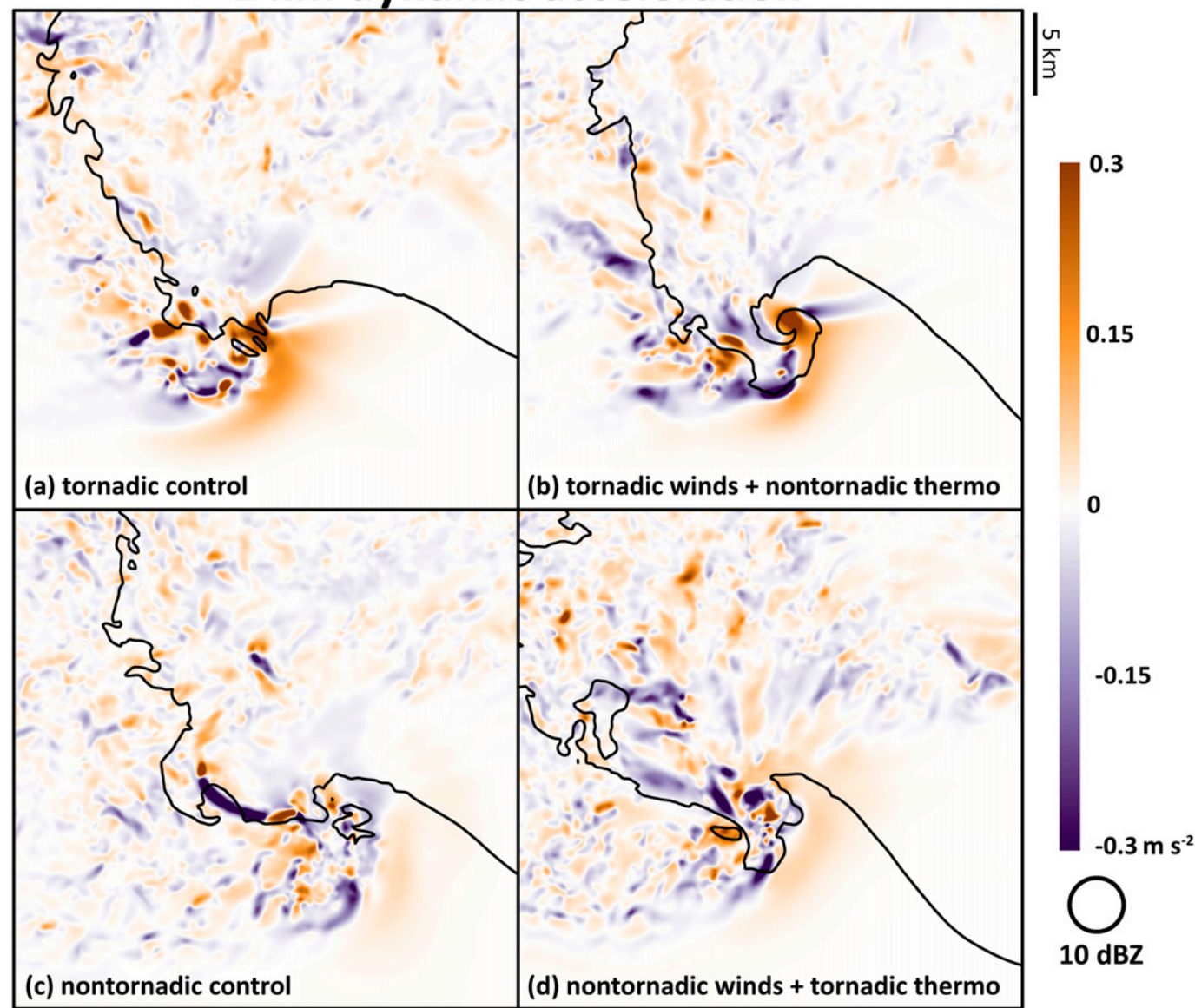

FIG. 23. As in Fig. 19, but for horizontal cross sections of $1 \mathrm{~km} \mathrm{AGL} \mathrm{dynamic} \mathrm{acceleration} \mathrm{(} \mathrm{m} \mathrm{s}^{-2}$; shaded).

well as a larger database of near-storm soundings, ${ }^{7}$ are needed in order to reliably determine whether such forecast metrics will lead to operationally useful boundaries between environments of nontornadic and significantly tornadic supercells.

The underlying motivation for this series of studies was to understand why strong low-level vertical shear is so favorable for tornadoes in proximity sounding studies (e.g., Markowski et al. 2003; Craven and Brooks 2004). The initial working hypothesis was that the production of surface vertical vorticity by a downdraft is directly influenced by the environmental wind profile (e.g., Dahl et al. 2014; Dahl 2015; Parker and Dahl 2015). The results

\footnotetext{
${ }^{7}$ As in Wade et al. (2018), who combined near-storm soundings from field projects such as VORTEX2 and the Mesoscale Predictability Experiment (Weisman et al. 2015; Trapp et al. 2016), among others.
}

presented herein, however, suggest otherwise. Since a preponderance of evidence suggests that essentially all surface-based supercells possess ample subtornadic surface vertical vorticity, operationally, it matters not how vertical vorticity is generated at the surface. Instead, the eventual fate of the abundant surface vertical vorticity is much more relevant. This is encouraging news because in operations, the strength and organization of the low-level mesocyclone is probably easier to diagnose and relate to the environment than processes occurring to produce vertical vorticity near the surface.

One caveat from $\mathrm{C} 17 \mathrm{a}, \mathrm{b}$, as well as this study, worth noting is that the thermodynamic differences between the nontornadic and tornadic VORTEX2 composites happen to be small within the context of the range of environments typically observed in nature (e.g., Thompson et al. 2003). This may have caused the lowertropospheric winds to be overemphasized in this series of studies. Additionally, while we have documented a 
recurring failure mode for tornadogenesis, it is likely that real storms have other failure modes than just what was present in these simulations herein. It is certainly possible that the failure mode for tornadogenesis documented herein and in C17a,b is not the only, or the dominant, failure mode for tornadogenesis across a much broader range of the supercell spectrum. Future work will test our conceptual model in more diverse environments (e.g., event and null cases from VORTEX2 and VORTEX-Southeast). Testing across a wide range of environments (regions, seasons, etc.) will provide a clearer sense of how the dynamical impacts of the lower-tropospheric winds compare to other sources of variability. Nevertheless, this work has consistently shown that within the parameter space encompassed by the VORTEX2 composite environments, the orientation of the near-surface horizontal vorticity is the dominant factor in the overall organization of the low-level mesocyclone, the eventual fate of subtornadic vertical vorticity, and thus the probability of tornadogenesis.

Acknowledgments. This research was supported by NSF Grant AGS-1748715 and NOAA Grants NA15OAR4590235 and NA16OAR4590213. We would like to acknowledge high-performance computing support from Yellowstone (ark:/85065/d7wd3xhc) provided by NCAR's Computational and Information Systems Laboratory, sponsored by the National Science Foundation. We especially thank Dr. George Bryan for his ongoing support of CM1. The first author's committee members (Drs. Johannes Dahl, Gary Lackmann, and Sandra Yuter) provided many useful suggestions and insights throughout this project. We also thank the three anonymous reviewers who provided invaluable feedback on this article.

\section{REFERENCES}

Anderson-Frey, A. K., Y. P. Richardson, A. R. Dean, R. L. Thompson, and B. T. Smith, 2016: Investigation of near-storm environments for tornado events and warnings. Wea. Forecasting, 31, 1771-1790, https://doi.org/10.1175/WAF-D-16-0046.1.

Blumberg, W. G., K. T. Halbert, T. A. Supinie, P. T. Marsh, R. L. Thompson, and J. A. Hart, 2017: SHARPpy: An open-source sounding analysis toolkit for the atmospheric sciences. Bull. Amer. Meteor. Soc., 98, 1625-1636, https://doi.org/10.1175/ BAMS-D-15-00309.1.

Brotzge, J., S. Erickson, and H. Brooks, 2011: A 5-yr climatology of tornado false alarms. Wea. Forecasting, 26, 534-544, https:// doi.org/10.1175/WAF-D-10-05004.1.

Bryan, G. H., and H. Morrison, 2012: Sensitivity of a simulated squall line to horizontal resolution and parameterization of microphysics. Mon. Wea. Rev., 140, 202-225, https://doi.org/ 10.1175/MWR-D-11-00046.1.
—, J. C. Wyngaard, and J. M. Fritsch, 2003: Resolution requirements for the simulation of deep moist convection. Mon. Wea. Rev., 131, 2394-2416, https://doi.org/10.1175/1520-0493 (2003) $131<2394:$ RRFTSO > 2.0.CO;2.

Bunkers, M. J., B. A. Klimowski, J. W. Zeitler, R. L. Thompson, and M. L. Weisman, 2000: Predicting supercell motion using a new hodograph technique. Wea. Forecasting, 15, 61-79, https://doi.org/ 10.1175/1520-0434(2000)015<0061:PSMUAN >2.0.CO;2.

Coffer, B. E., and M. D. Parker, 2015: Impacts of increasing lowlevel shear on supercells during the early evening transition. Mon. Wea. Rev., 143, 1945-1969, https://doi.org/10.1175/ MWR-D-14-00328.1.

_ and _ 2017: Simulated supercells in nontornadic and tornadic VORTEX2 environments. Mon. Wea. Rev., 145, 149180, https://doi.org/10.1175/MWR-D-16-0226.1.

,-- J. M. Dahl, L. J. Wicker, and A. J. Clark, 2017: Volatility of tornadogenesis: An ensemble of simulated nontornadic and tornadic supercells in VORTEX2 environments. Mon. Wea. Rev., 145, 4605-4625, https://doi.org/10.1175/MWR-D-17-0152.1.

Craven, J. P., and H. E. Brooks, 2004: Baseline climatology of sounding derived parameters associated with deep moist convection. Natl. Wea. Dig., 28 (1), 13-24.

Dahl, J. M., 2015: Near-ground rotation in simulated supercells: On the robustness of the baroclinic mechanism. Mon. Wea. Rev., 143, 4929-4942, https://doi.org/10.1175/MWR-D-15-0115.1.

— M. D. Parker, and L. J. Wicker, 2014: Imported and stormgenerated near-ground vertical vorticity in a simulated supercell. J. Atmos. Sci., 71, 3027-3051, https://doi.org/10.1175/ JAS-D-13-0123.1.

Davies, J. M., 2006: Tornadoes in environments with small helicity and/or high LCL heights. Wea. Forecasting, 21, 579-594, https://doi.org/10.1175/WAF928.1.

Davies-Jones, R., 1984: Streamwise vorticity: The origin of updraft rotation in supercell storms. J. Atmos. Sci., 41, 2991-3006, https:// doi.org/10.1175/1520-0469(1984)041<2991:SVTOOU >2.0.CO;2.

- - 2015: A review of supercell and tornado dynamics. Atmos. Res., 158-159, 274-291, https://doi.org/10.1016/ j.atmosres.2014.04.007.

— and H. Brooks, 1993: Mesocyclogenesis from a theoretical perspective. The Tornado: Its Structure, Dynamics, Prediction, and Hazards, Geophys. Monogr., Vol. 79, Amer. Geophys. Union, 105-114, https://doi.org/10.1029/GM079p0105.

_ - R. J. Trapp, and H. B. Bluestein, 2001: Tornadoes and tornadic storms. Severe Convective Storms, Meteor. Monogr., No. 50, Amer. Meteor. Soc., 167-222, https://doi.org/ 10.1175/0065-9401-28.50.167.

Deardorff, J. W., 1980: Stratocumulus-capped mixed layers derived from a three-dimensional model. Bound.-Layer Meteor., 18, 495-527, https://doi.org/10.1007/BF00119502.

Esterheld, J. M. and D. J. Giuliano, 2008: Discriminating between tornadic and non-tornadic supercells: A new hodograph technique. Electron. J. Severe Storms Meteor., 3 (2), http:// www.ejssm.org/ojs/index.php/ejssm/article/viewArticle/33.

French, M. M., D. W. Burgess, E. R. Mansell, and L. J. Wicker, 2015: Bulk hook echo raindrop sizes retrieved using mobile, polarimetric Doppler radar observations. J. Appl. Meteor. Climatol., 54, 423-450, https://doi.org/10.1175/JAMC-D-14-0171.1.

Grzych, M. L., B. D. Lee, and C. A. Finley, 2007: Thermodynamic analysis of supercell rear-flank downdrafts from Project ANSWERS. Mon. Wea. Rev., 135, 240-246, https://doi.org/ 10.1175/MWR3288.1.

Guarriello, F., C. Nowotarski, and C. Epifanio, 2018: Effects of the low-level wind profile on outflow position and near-surface 
vertical vorticity in simulated supercell thunderstorms. J. Atmos. Sci., 75, 731-753, https://doi.org/10.1175/JAS-D-17-0174.1.

Hampshire, N. L., R. M. Mosier, T. M. Ryan, and D. E. Cavanaugh, 2018: Relationship of low-level instability and tornado damage rating based on observed soundings. J. Operational Meteor., 6 (1), 1-12, https://doi.org/10.15191/nwajom.2018.0601.

Honda, T., and T. Kawano, 2016: A possible mechanism of tornadogenesis associated with the interaction between a supercell and an outflow boundary without horizontal shear. J. Atmos. Sci., 73, 1273-1292, https://doi.org/10.1175/JAS-D-14-0347.1.

Klemp, J. B., and R. B. Wilhelmson, 1978: The simulation of threedimensional convective storm dynamics. J. Atmos. Sci., 35, 1070-1096, https://doi.org/10.1175/1520-0469(1978)035<1070: TSOTDC $>2.0 . \mathrm{CO} ; 2$.

Kumjian, M. R., 2011: Precipitation properties of supercell hook echoes. Electron. J. Severe Storms Meteor., 6 (5), http://ejssm.org/ ojs/index.php/ejssm/article/viewArticle/93.

- Z, Z. J. Lebo, and H. C. Morrison, 2015: On the mechanisms of rain formation in an idealized supercell storm. Mon. Wea. Rev., 143, 2754-2773, https://doi.org/10.1175/ MWR-D-14-00402.1.

Mansell, E. R., 2010: On sedimentation and advection in multimoment bulk microphysics. J. Atmos. Sci., 67, 3084-3094, https://doi.org/10.1175/2010JAS3341.1.

— C. L. Ziegler, and E. C. Bruning, 2010: Simulated electrification of a small thunderstorm with two-moment bulk microphysics. J. Atmos. Sci., 67, 171-194, https://doi.org/10.1175/ 2009JAS2965.1.

Markowski, P. M., 2002: Hook echoes and rear-flank downdrafts: A review. Mon. Wea. Rev., 130, 852-876, https://doi.org/10.1175/ 1520-0493(2002)130<0852:HEARFD>2.0.CO;2.

- 2016: An idealized numerical simulation investigation of the effects of surface drag on the development of near-surface vorticity in supercell thunderstorms. J. Atmos. Sci., 73, 43494385, https://doi.org/10.1175/JAS-D-16-0150.1.

_ , and Y. P. Richardson, 2014: The influence of environmental low-level shear and cold pools on tornadogenesis: Insights from idealized simulations. J. Atmos. Sci., 71, 243-275, https:// doi.org/10.1175/JAS-D-13-0159.1.

— , and — , 2017: Large sensitivity of near-surface vertical vorticity development to heat sink location in idealized simulations of supercell-like storms. J. Atmos. Sci., 74, 1095-1104, https://doi.org/10.1175/JAS-D-16-0372.1.

—, J. M. Straka, and E. N. Rasmussen, 2002: Direct surface thermodynamic observations within the rear-flank downdrafts of nontornadic and tornadic supercells. Mon. Wea. Rev., 130, 1692-1721, https://doi.org/10.1175/1520-0493(2002)130<1692: DSTOWT $>2.0 . \mathrm{CO} ; 2$.

— C. Hannon, J. Frame, E. Lancaster, A. Pietrycha, R. Edwards, and R. L. Thompson, 2003: Characteristics of vertical wind profiles near supercells obtained from the Rapid Update Cycle. Wea. Forecasting, 18, 1262-1272, https://doi.org/10.1175/1520-0434 (2003)018<1262:COVWPN $>2.0 . \mathrm{CO} ; 2$.

— Y. P. Richardson, E. Rasmussen, J. Straka, R. Davies-Jones, and R. J. Trapp, 2008: Vortex lines within low-level mesocyclones obtained from pseudo-dual-Doppler radar observations. Mon. Wea. Rev., 136, 3513-3535, https://doi.org/10.1175/ 2008MWR2315.1.

McCaul, E. W., and M. L. Weisman, 2001: The sensitivity of simulated supercell structure and intensity to variations in the shapes of environmental buoyancy and shear profiles. Mon. Wea. Rev., 129, 664-687, https://doi.org/10.1175/1520-0493(2001)129<0664: TSOSSS $>2.0 . \mathrm{CO} ; 2$.
Naylor, J., and M. S. Gilmore, 2012: Convective initiation in an idealized cloud model using an updraft nudging technique. Mon. Wea. Rev., 140, 3699-3705, https://doi.org/10.1175/ MWR-D-12-00163.1.

- - and - - 2014: Vorticity evolution leading to tornadogenesis and tornadogenesis failure in simulated supercells. J. Atmos. Sci., 71, 1201-1217, https://doi.org/ 10.1175/JAS-D-13-0219.1.

Okubo, A., 1970: Horizontal dispersion of floatable particles in the vicinity of velocity singularities such as convergences. Deep-Sea Res., 17, 445-454, https://doi.org/10.1016/ 0011-7471(70)90059-8.

Orf, L., R. Wilhelmson, B. Lee, C. Finley, and A. Houston, 2017: Evolution of a long-track violent tornado within a simulated supercell. Bull. Amer. Meteor. Soc., 98, 45-68, https://doi.org/ 10.1175/BAMS-D-15-00073.1.

Parker, M. D., 2014: Composite VORTEX2 supercell environments from near-storm soundings. Mon. Wea. Rev., 142, 508-529, https://doi.org/10.1175/MWR-D-13-00167.1.

_ 2017: How much does "backing aloft" actually impact a supercell? Wea. Forecasting, 32, 1937-1957, https://doi.org/ 10.1175/WAF-D-17-0064.1.

— and J. M. Dahl, 2015: Production of near-surface vertical vorticity by idealized downdrafts. Mon. Wea. Rev., 143, 2795-2816, https://doi.org/10.1175/MWR-D-14-00310.1.

Rasmussen, E. N., 2003: Refined supercell and tornado forecast parameters. Wea. Forecasting, 18, 530-535, https://doi.org/ 10.1175/1520-0434(2003)18<530:RSATFP $>2.0$.CO;2.

Riganti, C. J., and A. L. Houston, 2017: Rear-flank outflow dynamics and thermodynamics in the 10 June 2010 Last Chance, Colorado, supercell. Mon. Wea. Rev., 145, 2487-2504, https:// doi.org/10.1175/MWR-D-16-0128.1.

Schenkman, A. D., M. Xue, and D. T. Dawson II, 2016: The cause of internal outflow surges in a high-resolution simulation of the 8 May 2003 Oklahoma City tornadic supercell. J. Atmos. Sci., 73, 353-370, https://doi.org/10.1175/JAS-D-15-0112.1.

Shu, C.-W., 2003: High-order finite difference and finite volume WENO schemes and discontinuous Galerkin methods for CFD. Int. J. Comput. Fluid Dyn., 17, 107-118, https://doi.org/ 10.1080/1061856031000104851.

Thompson, R. L., R. Edwards, J. A. Hart, K. L. Elmore, and P. Markowski, 2003: Close proximity soundings within supercell environments obtained from the Rapid Update $\mathrm{Cy}$ cle. Wea. Forecasting, 18, 1243-1261, https://doi.org/10.1175/ 1520-0434(2003)018<1243:CPSWSE > 2.0.CO;2.

_ C. M. Mead, and R. Edwards, 2007: Effective storm-relative helicity and bulk shear in supercell thunderstorm environments. Wea. Forecasting, 22, 102-115, https://doi.org/10.1175/ WAF969.1.

— B. T. Smith, J. S. Grams, A. R. Dean, and C. Broyles, 2012: Convective modes for significant severe thunderstorms in the contiguous United States. Part II: Supercell and QLCS tornado environments. Wea. Forecasting, 27, 1136-1154, https:// doi.org/10.1175/WAF-D-11-00116.1.

Trapp, R. J., G. J. Stumpf, and K. L. Manross, 2005: A reassessment of the percentage of tornadic mesocyclones. Wea. Forecasting, 20, 680-687, https://doi.org/10.1175/WAF864.1. , D. J. Stensrud, M. C. Coniglio, R. S. Schumacher, M. E. Baldwin, S. Waugh, and D. T. Conlee, 2016: Mobile radiosonde deployments during the Mesoscale Predictability Experiment (MPEX): Rapid and adaptive sampling of upscale convective feedbacks. Bull. Amer. Meteor. Soc., 97, 329-336, https://doi.org/10.1175/BAMS-D-14-00258.1. 
Wade, A. R., M. C. Coniglio, and C. L. Ziegler, 2018: Comparison of near- and far-field supercell inflow environments using radiosonde observations. Mon. Wea. Rev., 146, 2403-2415, https://doi.org/10.1175/MWR-D-17-0276.1.

Weisman, M. L., and Coauthors, 2015: The Mesoscale Predictability Experiment (MPEX). Bull. Amer. Meteor. Soc., 96, 2127-2149, https://doi.org/10.1175/BAMS-D-13-00281.1.

Weiss, C. C., D. C. Dowell, J. L. Schroeder, P. S. Skinner, A. E. Reinhart, P. M. Markowski, and Y. P. Richardson, 2015: A comparison of near-surface buoyancy and baroclinity across three VORTEX2 supercell intercepts. Mon. Wea. Rev., 143 2736-2753, https://doi.org/10.1175/MWR-D-14-00307.1.

Weiss, J., 1991: The dynamics of enstrophy transfer in twodimensional hydrodynamics. Physica D, 48, 273-294, https:// doi.org/10.1016/0167-2789(91)90088-Q.

Wicker, L. J., and W. C. Skamarock, 2002: Time-splitting methods for elastic models using forward time schemes. Mon. Wea.
Rev., 130, 2088-2097, https://doi.org/10.1175/1520-0493(2002) $130<2088$ :TSMFEM $>2.0$. CO 2 .

Wilhelmson, R. B., and C.-S. Chen, 1982: A simulation of the development of successive cells along a cold outflow boundary. J. Atmos. Sci., 39, 1466-1483, https://doi.org/10.1175/ 1520-0469(1982)039<1466:ASOTDO >2.0.CO;2.

Wurman, J., D. Dowell, Y. Richardson, P. Markowski, E. Rasmussen, D. Burgess, L. Wicker, and H. B. Bluestein, 2012: The second Verification of the Origins of Rotation in Tornadoes Experiment: VORTEX2. Bull. Amer. Meteor. Soc., 93, 1147-1170, https://doi.org/10.1175/ BAMS-D-11-00010.1.

Ziegler, C. L., 1985: Retrieval of thermal and microphysical variables in observed convective storms. Part I: Model development and preliminary testing. J. Atmos. Sci., 42, 14871509, https://doi.org/10.1175/1520-0469(1985)042<1487: ROTAMV $>2.0 . \mathrm{CO} ; 2$. 